\title{
ENTREVISTA A ANTONIO-ENRIQUE PÉREZ LUÑO
}

\author{
INTERVIEW TO ANTONIO-ENRIQUE \\ PÉREZ LUÑO
}

\author{
Manuel Atienza \\ Universidad de Alicante \\ manuel.atienza@ua.es
}

\begin{abstract}
Manuel Atienza: En una publicación reciente has explicado que tus «años de aprendizaje» transcurrieron, primero, en Barcelona, en donde cursaste la licenciatura en Derecho, y luego, en diversas universidades europeas, como Bolonia, en donde biciste tu tesis de doctorado, en Friburgo y en Heidelberg. También señalas abi que tus principales maestros habrian sido LUÑO PEÑA, FASSÒ, Erik WOLF, TRUYOL Y SERRA y, creo entender, DELGADO PINTO. ¿Podrías darnos algunos detalles sobre todo ello? ¿Qué te llevó a estudiar Derecho? ¿Qué recuerdos tienes de la Universidad de Barcelona de entonces? ¿Qué destacarías de cada uno de los cinco profesores mencionados?
\end{abstract}

Antonio-Enrique Pérez Luño: Lo que me preguntas me lleva a rememorar el tiempo y las causas que motivaron mi vocación jurídica. Esa mirada al pasado, que entraña siempre ciertas dosis de nostalgia y melancolía, me retrotrae a mis últimos cursos de bachillerato y, en particular, al Preuniversitario. Durante esa etapa inicial de lo que GOETHE denomina años de aprendizaje (LehrerJahre), fui alumno del Instituto Jaime Balmes de Barcelona. Dicho Centro contaba entonces con cualificados docentes de filosofía y de ciencias sociales, que contribuyeron a decantar mi interés por estas materias.

No puedo tampoco soslayar el influjo de mi tío, el profesor Enrique LuÑo PEÑA, en mi decisión de optar por el estudio del Derecho. Su magisterio suscitó mi interés por los clásicos de nuestro pensamiento filosófico, jurídico y político. Tuvo siempre la convicción de que, sin el conocimiento del pasado, no sería posible comprender ni establecer una relación intelectual provechosa con el pensamiento del presente.

Mi formación jurídica se desarrolló en el decurso de la Licenciatura en Derecho en la Universidad de Barcelona, donde recibí la docencia de algunos profesores de denso prestigio, en una atmósfera, la de los años sesenta del pasado siglo, de gran efervescencia política, en la que el compromiso de muchos profesores y alumnos con la reivindicación de las libertades y del Estado de Derecho presagiaban los aconteceres que tuvieron lugar algunos años más tarde. 
Cursé también estudios de Derecho Comparado en las Universidades de Trieste y Coímbra, culminándolos en la Facultad Internacional de Derecho Comparado de Estrasburgo. Dichos estudios me permitieron acceder al conocimiento de los aspectos nucleares de los sistemas jurídicos contemporáneos e iniciar la comprensión de lo que Gustav RADBRUCH denominó «el espíritu del Common Law».

Elaboré mi tesis doctoral en la Universidad de Bolonia, como becario del Real Colegio de España, en una época en la que la cultura jurídica italiana había adquirido un protagonismo internacional relevante. En dicha Universidad gocé de la circunstancia favorable de que mi tesis fuera dirigida por uno de los grandes maestros de la historiografía filosófico-jurídica del siglo Xx: el profesor Guido FAssò. Le debo el haberme enseñado el método y el rigor de la investigación del Derecho y, a la vez, el haberme imbuido el deber de tratar los problemas filosófico-jurídicos como problemas de conciencia. Le agradaba invocar la máxima del poeta italiano Giuseppe CARDUCCI, «essere e non parere», porque para FASSÒ lo que importaba era el ser, no el aparentar.

Ha sido FAssò uno de los más destacados renovadores del iusnaturalismo en la cultura contemporánea. Debe tenerse presente que su concepción del Derecho natural no es la del código eterno e inmutable, trascendente a la historia, que para él será, como ya lo había sido para CARNELUTTI: «L'idolo che non dobbiamo adorare», sino el Derecho natural de una razón que no niega la historia. Porque FAssò siguió la enseñanza de Giambattista VICO, para quien el Derecho natural es universal, pero se realiza en la historia y se manifiesta en las instituciones jurídicas de los pueblos, alcanzando forma racional en la última fase del progreso de las naciones.

Al comentar la teoría iusnaturalista de FASSÒ, he tomado en préstamo la distinción de ORTEGA Y GASSET entre ideales y arquetipos. Los conceptos ideales son categorías de estricto deber ser; se trata del puro deseo sobre cómo deberían ser las cosas para su perfección. El arquetipo, por el contrario, hace referencia a aquellas realidades que nos parecen las mejores, o sea, a manifestaciones empíricas de perfección. La noción de Derecho natural de FASSÒ estimo que sitúa a esta categoría en el ámbito de los arquetipos y no en el de los ideales. No huelga recordar que, para FAssò, el sistema del Common Law supone la expresión empírica e histórica en la que se han concretado y expresado determinados principios del Derecho natural. Asimismo consideró que determinados valores y principios del Derecho natural se hallan consagrados hoy por la jurisprudencia constitucional de los Estados de Derecho.

Durante mi permanencia en la Universidad de Friburgo de Brisgovia, tuve la grata ocasión de conocer y de recibir las enseñanzas del profesor Erik WOLF, una de las grandes cimas de la cultura jurídica de nuestro tiempo. Erik WOLF fue el legatario intelectual de Gustav RADBRUCH, de quien publicó la edición póstuma de su Rechtsphilosophie. El profesor Wolf había sido decano de la Facultad de Derecho de la Universidad de Heidelberg durante la etapa del rectorado de Martín HeIDEgGER y sufrió la perversión del orden jurídico que se produjo durante la Alemania nazi. Fue un estudioso atento del historicismo jurídico germano y del iusnaturalismo humanista del último RADBRUCH y ello le permitió ofrecer una visión, en clave histórica, de la axiología jurídica, es decir, de la idea de la justicia y del Derecho natural. Esos planteamientos influyeron, decisivamente, en mi propia concepción iusfilosófica. 
Traté asiduamente y recibí el fecundo magisterio de un gran filósofo del Derecho e internacionalista: Antonio TRUYOL y SERRA. Ambos coincidimos como investigadores del Max Planck en Heidelberg y recuerdo, con nostalgia, nuestros paseos por un paraje pleno de resonancias culturales: Auf den Philosophen Weg (el camino de los filósofos), en el que cada una de sus conversaciones resultaba para mí una lección magistral. Poco antes de su muerte, recibí de él el encargo más importante de toda mi vida académica. Se trataba de hacerme responsable de la edición del tercer volumen de su célebre Historia de Filosofía del Derecho y del Estado. Gracias a la inestimable ayuda de su hija Marilena TRUYOL WINTRICH pudimos publicar ese volumen, que, estimo, no desmerece de los dos anteriores.

Mi labor docente se inició en la Universidad de Barcelona, en la que desempeñé el puesto de ayudante y de profesor adjunto, entre los años 1969 y 1973. A finales de ese último año, obtuve por oposición la plaza de profesor agregado de Filosofía del Derecho en la Universidad de Salamanca. Puedo suscribir, en su integridad, el aserto de Miguel DE CERVANTES, quien en El licenciado Vidriera afirma que «Salamanca hechiza la voluntad de quien de la paz de su vivienda ha gustado». Debo decir que durante cinco años gocé de la paz y serenidad de la vida salmantina y que comprobé el hechizo que, todavía hoy, ejerce la Universidad de Salamanca sobre todo en el ámbito cultural de habla hispana.

Mi destino académico en la Universidad de Salamanca me permitió incorporarme al Área de Filosofía del Derecho, que dirigía, de forma ejemplar, el profesor José DELGADO PINTO. Su impronta intelectual ha sido fértil y persistente en cuantos tuvimos la oportunidad de tratarle y recibir sus enseñanzas. Formado en el iusnaturalismo clásico y moderno, el profesor DELGADO PINTO sintió luego la atracción intelectual por el normativismo kelseniano, que asumió siempre desde una perspectiva crítica. Indagó también, con modélica dedicación y rigor, las tesis de alguna de las principales figuras contemporáneas de la Filosofía y la Teoría jurídica, como RECASENS SICHES, HART, Ross, RAWLS, DwORKIN, FINNIS..., sobre cuyo pensamiento dirigió o sugirió tesis doctorales relevantes.

He tenido, por tanto, la fortuna de recibir el magisterio de cualificados historiadores de la filosofía jurídica. Si sus concepciones historiográficas fueron distintas, tal vez antagónicas, lo indiscutible ha sido su virtualidad para imbuirme la pasión por la historia del pensamiento jurídico y político. La vocación hacia el pasado nunca, desde entonces, me ha abandonado, por más que en años sucesivos he dedicado preferentemente mi atención a aspectos actuales de la Teoría y la Filosofía jurídica.

M. A.: Me ha interesado mucho esa distinción de ORTEGA a la que te refieres, entre ideales y arquetipos, y la aplicación al caso del Derecho natural. Me parece que tiene un gran poder de clarificación, pero al mismo tiempo abre, yo creo, algunas dudas que quisiera plantearte y que se refieren a cómo entiendes tú exactamente el Derecho natural.

En principio, como lo has señalado en muchas ocasiones, sería un iusnaturalismo no de carácter ontológico, sino deontológico. Pero me parece que la distinción orteguiana rompe de alguna manera esa distinción; o sea, tu iusnaturalismo sería deontológico desde la perspectiva del concepto ideal de Derecho natural, pero ontológico cuando se considera el arquetipo del Estado de Derecho y la jurisprudencia constitucional. ¿Es así? Pero ade- 
más (este sería para mí el punto más importante) una cosa es que determinados principios y valores de lo que solemos llamar el constitucionalismo contemporáneo tengan su origen en la tradición iusnaturalista (mejor, como tú muy bien sabes, en cierta tradición iusnaturalista), y otra que debamos interpretarlos boy en forma iusnaturalista.

Lo primero me parece indiscutible, pero lo que no veo yo tan claro es lo segundo: que debamos seguir siendo iusnaturalistas. Y aqui viene entonces mi pregunta. ¿En qué consiste exactamente tu iusnaturalismo? ¿Cómo se diferenciaría boy — si es que puede diferenciarse - una concepción iusnaturalista de la justicia (y de la interpretación constitucional) de otras concepciones que suscriben la tesis de la objetividad en materia moral (como pudiera ser el caso de RAWLS o de DWORKIN) pero que no son iusnaturalistas? ¿O en tu opinión deberíamos identificar el iusnaturalismo (como concepción de la moral, de la justicia) con objetivismo moral? Si no es así, ¿cuáles son las diferencias específicas de la concepción iusnaturalista, en relación con el resto de las teorias éticas objetivistas?

A.-E. P. L.: Como indicas, mi concepción del Derecho natural es deontológica. Me parece que es preferible a las versiones iusnaturalistas ontológicas, que identifican el Derecho con la justicia, de conformidad con la célebre fórmula tomista: ius est quod iustum est. Estimo, por el contrario, que el Derecho positivo injusto no deja de ser Derecho, aunque sea un Derecho injusto. El iusnaturalismo deontológico prescribe los valores que deben informar el Derecho positivo para que sea justo. Esos valores no se hallan fuera de la experiencia y de la historia. Se trata de aquellos valores o exigencias de justicia que la razón práctica identifica, como arquetipos, en las manifestaciones de la moralidad pública, en particular, en las dirigidas a satisfacer necesidades radicales, o en las formas más perfectas de la experiencia jurídica. Como es evidente, no todas las manifestaciones empíricas de juridicidad constituyen arquetipos, es decir, entrañan valores de perfección. Se puede sintetizar esta tesis invirtiendo la célebre fórmula hegeliana, en los siguientes términos: todo lo racional debe ser real, pero no todo lo real es racional. De ahí, que, en lo que respecta a mi postura, no estimo que exista confusión entre los planos deontológico y ontológico de los valores jurídicos.

No pretendo sustentar la tesis de que la tradición iusnaturalista, en concreto su versión humanista y racionalista, sea la única que haya contribuido a la formación del constitucionalismo. En el constitucionalismo del presente se hallan involucradas tradiciones jurídico-políticas y teorías sobre el Derecho y el Estado de muy distinto signo. Baste aludir a la tradición británica del parlamentarismo, a la francesa de la división de poderes, a las tesis kelsenianas sobre la defensa de la Constitución por parte del Tribunal Constitucional y de una jurisdicción constitucional concentrada, a la tutela jurisdiccional de los derechos fundamentales, a partir de las experiencias germana e italiana y del amparo latinoamericano..., estas aportaciones de la cultura iuspublicista han tenido una relevancia decisiva en la conformación de la estructura y de las garantías del constitucionalismo presente, contribuyen a una correcta inteligencia de los sistemas constitucionales actuales y son independientes del iusnaturalismo. Pero, al propio tiempo, creo que el iusnaturalismo permite una interpretación más consciente, aunque no sea la única posible, del sistema de valores, principios y derechos fundamentales constitucionales. Ello es debido a que auspicia una interpretación del sistema axiológico constitucional vertebrada en esa tradición del humanismo racionalista 
iusnaturalista en el que la mayoría de esas categorías axiológicas se forjaron y que, por tanto, permiten también su mejor comprensión actual.

Tienes razón cuando señalas que el objetivismo ético suele considerarse como un rasgo identificador del iusnaturalismo y que, no obstante, esa postura puede defenderse también desde premisas teóricas ajenas al Derecho natural. Debo aclarar, al respecto, que, para mí, el objetivismo de los valores no representa un rasgo constitutivo del iusnaturalismo. He intentado evitar los extremos de la Escila y Caribdis que representan las versiones radicales del objetivismo y el subjetivismo axiológicos. Estimo que los valores que informan el contenido del Derecho natural no pueden concebirse como un sistema estático de principios absolutos situados en una esfera ideal anterior e independiente de la experiencia, como pretende el objetivismo; pero tampoco pueden reducirse al plano de los deseos o intereses de los individuos, como propugna el subjetivismo. Siempre he sentido desconfianza respecto a las tesis que propugnan un orden objetivo, de valores apriorísticos y necesarios, porque existe el riesgo de que algunos miembros de la sociedad especialmente dotados (los filósofos, según PLATÓN), sintiéndose intérpretes y portavoces de ese orden axiológico objetivo, trate de imponer una «tiranía de valores» a los demás; lo que es abiertamente incompatible con un sistema ético, jurídico y político pluralista. No menos insatisfactorias me han parecido y me parecen determinadas versiones del subjetivismo que, al extremar su matriz individualista, engendran formas de decisionismo, de relativismo o de la propia «anarquía de los valores».

Frente a estas posturas he abogado por un intersubjetivismo axiológico, que parte de la posibilidad de llegar a establecer las condiciones que permiten a la racionalidad práctica llegar a un cierto consenso abierto y revisable, sobre el fundamento de los valores que sustentan el Derecho natural.

Mi postura ha intentado ser una mediación crítica entre dos tesis ligadas a la fundamentación contemporánea de los valores, de inequívoco signo antidogmático y humanista: la teoría consensual de la verdad elaborada por el último de los teóricos de la Escuela de Francfort, Jürgen HABERMAS; y la filosofía de las necesidades radicales defendida por la Escuela de Budapest y, de modo especial, por Agnes HeLlER. La primera proporciona el marco metódico, las condiciones ideales a que debe someterse el discurso racional fundamentador de los valores, así como a contrario sensu denuncia los factores que en las sociedades históricas distorsionan o impiden la posibilidad de llegar a legitimaciones racionales de los valores generalizables o universalizables en cuanto dotadas de «objetividad intersubjetiva». La segunda ha aportado datos relevantes sobre las condiciones antropológicas, sobre las exigencias o necesidades de la naturaleza humana que constituyen la base material u objetiva de todo valor.

Debo reconocer que mis tesis sobre el Derecho natural han sido consideradas por algunos analistas críticos, que lo conciben como un orden suprahistórico, metafísico, ideal, objetivo y dogmático, como ajenas o incompatibles con el iusnaturalismo. Debo aducir, sobre este punto, que en su milenaria y multiforme trayectoria, el iusnaturalismo no se identifica, en muchas ocasiones, con esa caracterización. Nunca me ha parecido plausible la tesis de que existe un único concepto «auténtico» del Derecho natural. Esa pretensión me parece un lecho de Procusto teórico, de carácter rígido y dogmático. Quizá convenga recordar sobre ello que Erik WoLf, al analizar la polise- 
mia del término «Derecho natural», pudo distinguir doce formas distintas de concebir la noción de «naturaleza» en dicha expresión y diez acepciones diferentes del término «Derecho» en la formación de aquel concepto. No menos multívoca y equívoca es la noción del «positivismo jurídico». Así, en el Coloquio de Bellagio Sul positivismo giuridico, de 1960, los profesores norteamericanos FALK y SHUMAN registraron más de 30 versiones diferentes de dicha expresión.

En la actualidad, las versiones renovadoras del iusnaturalismo, abiertas a la historia, deontológicas y críticas y las revisiones del positivismo jurídico, tales como el denominado «positivismo jurídico incluyente», el positivismo crítico o el postpositivismo, poseen fronteras lábiles e imprecisas. Por eso, los debates actuales entre iusnaturalistas, iuspositivistas y los que podríamos denominar «alternativistas», es decir, quienes desean situar el plano orbital de su concepción jurídica más allá de esa dicotomía, desembocan, las más de la veces, en pura logomaquia, ante la dificultad que entraña discernir qué es a lo que se apela cuando se emplean esos términos o etiquetas doctrinales.

De cuanto llevo dicho se desprende, a grandes rasgos, mi caracterización del Derecho natural. Soy consciente, empero, que para no eludir tu pregunta, debo concretar, en mayor medida, el sentido de mi iusnaturalismo. Ese empeño requeriría una reflexión más demorada en pormenores, que aquí no procede, porque una entrevista exige concisión y yo no deseo transgredir esa pauta. En aras de ello, estimo que mi concepción del Derecho natural se puede resumir (todo resumen corre el riesgo de dejar cabos sueltos) a partir de las siguientes premisas:

a) Es una teoría deontológica del Derecho, que prescribe cuales deben ser los valores que deben informar el Derecho para que sea justo y que suministra argumentos para la crítica del Derecho injusto. Se trata de lo que la doctrina iusnaturalista denomina «la función histórica del Derecho natural»: servir de modelo a la normatividad positiva y de instancia crítica del Derecho injusto.

b) Es una teoría arquetípica e intersubjetivista o basada en una objetividad intersubjetiva de los valores jurídicos. Estos son concebidos como aquellas manifestaciones que la moralidad pública más inmediatamente vinculada a la satisfacción de necesidades humanas radicales, o aquellas experiencias de perfección jurídica que la racionalidad práctica establece, a través del consenso intersubjetivo.

c) Es una teoría pluralista de las fuentes del Derecho. Sustenta la idea de que el Derecho no se identifica, ni se agota en la ley, sino que es necesario admitir otros cauces de producción normativa. Relevancia especial adquieren, en esta concepción pluralista del ordenamiento jurídico, los principios, a través de los cuales se expresan arquetipos de moralidad y de juridicidad que deben informar el Derecho.

M. A.: Soy consciente de que una entrevista no es el lugar adecuado para presentar de manera adecuada una concepción del Derecho natural, pero no puedo evitar aprovechar la ocasión para pedirte nuevas precisiones y desarrollos (lo que, estoy seguro, el lector de Doxa agradecerá) sobre algunas de tus anteriores afirmaciones. Así, el Derecho natural es para ti una teoría deontológica, pero que sirve (la has utilizado) para aplicarla a problemas de interpretación constitucional, en cuyo caso, el Derecho natural cumpliría la función de dar un sentido adecuado al Derecho, no de criticarlo. $O$, para decirlo de otra manera, la distinción entre el Derecho natural deontológico y el ontológico parecería presuponer una distinción más o menos nitida entre el deber ser y el ser, entre prescribir y describir, etc. 
¿Pero es esa tu posición? Otra cuestión. En la anterior respuesta hablas de «objetivo» «objetivismo» u «objetividad» en dos sentidos: uno es peyorativo (cuando te refieres al orden objetivo de valores), pero otro no (cuando a lo que aludes es a la «objetividad intersubjetiva»). ¿Podrías precisarnos entonces cómo habría que entender esto último, es decir, cómo entiendes tú el «consenso intersubjetivo»? Me parece que a lo que te refieres con ello es a alguna combinación de consenso fáctico y consenso racional, ideal, ¿pero es así?

A.-E. P. L.: Como indicas, mi tesis sobre el Derecho natural combina el plano deontológico, en cuanto lo concibe como modelo y crítica de la positividad, con su dimensión arquetípica que se manifiesta en las expresiones del Derecho correcto. Esto supone, en efecto, una distinción entre el ser y el deber ser. A partir de esta observación, con sutil pericia dialéctica (no en vano eres nuestro más cualificado tratadista de la argumentación), me sitúas ante la vexata quaestio de la naturalistic fallacy, que ha sido el Cabo de Hornos o el cabo de los naufragios de numerosas teorías axiológicas contemporáneas. Soy consciente de que a mi propuesta de distinción, pero sin separación, entre el ser y el deber ser, se le puede objetar que implica una forma de falacia naturalista, al derivar del dato empírico de la moralidad social, de las experiencias jurídicas de perfección y de las necesidades, el sistema de los valores jurídicos.

Sobre este punto resulta obligado recordar que, incluso en el seno de la filosofía moral analítica más reciente, se ha matizado la observación célebre de David HumE, formulada expresamente por George Edward MOORE, de que cualquier intento de derivar conceptos normativos de datos descriptivos incurre en una falacia naturalista. Así, por ejemplo, incluso quienes como Karl POPPER aceptan en principio la imposibilidad lógica de derivar los valores de los hechos, reconocen que los valores, a menudo, tienen que ver con hechos o están conectados con hechos. Sin que hayan faltado intentos, como el de Stephen E. Toulmin, por mostrar la peculiaridad de la argumentación ética a través de la cual puede pasarse de fundamentos descriptivos a una conclusión ética, mediante la inferencia valorativa. Todavía ha ido más lejos John SEARLE en su intento de mostrar cómo, en determinados casos, es posible la derivación del deber ser a partir del ser, incluso respetando las reglas tradicionales de la lógica deductiva.

Desde las premisas de una concepción del Derecho natural deontológico y arquetípico, se parte del principio viquiano del verum ipsum factum, de que solo se conocen las cosas que se han hecho (por tanto, también los valores) de los que se tiene experiencia y se acepta la exigencia de continuidad entre los postulados teóricos y la praxis.

Dices, y dices bien, en tu pregunta que empleo el término objetivismo con un sentido peyorativo, mientras que me decanto por una objetividad intersubjetiva. Intentaré precisar este planteamiento. He tratado de apartarme de una concepción axiológica objetivista, que concibe los valores como categorías apriorísticas, irreales, dotadas de una objetividad independiente de las determinaciones humanas. Desde premisas objetivistas fundadas en la fenomenología, se ha aludido a un ejemplo que pretende poseer el mérito de compendiar y clarificar el núcleo de la hipercompleja y abstrusa concepción fenomenológica de los valores. Según la estimativa, basada en la ética material de los valores, pero que es predicable de toda actitud objetivista, estos valen con independencia de la realidad y de cualquier voluntad subjetiva. En ocasiones, se ha intentado ejemplificar y clarificar el objetivismo, con la remisión a un fragmento de una 
obra teatral de SHAKESPEARE (Troilo y Crésida). Discutiendo Héctor y Troilo sobre el caso Helena, reparte el dramaturgo entre ellos las dos teorías de valor: la subjetivista y la objetivista. «Hermano - dice Héctor- ella no vale lo que nos cuesta conservarla». Y Troilo: «¿Qué valor puede tener una cosa sino el que nosotros le demos?». A lo que Héctor replica con estas palabras: «No, el valor no depende de la querencia individual; tiene su propia estimación y dignidad, que le compete no menos en sí mismo que en la apreciación del hombre».

Se nos presenta el valor como una entidad válida por sí, al margen de cualquier connotación real o experiencial: no es una quaestio facti, sino una pura elucubración intelectual. Porque lo que Héctor no nos dice es qué gurú va a ser el vocero de los valores. Si estos permanecen en el ámbito de la elección individual, se incurre en el subjetivismo. Si desde el objetivismo se invocan las intuiciones eidéticas generalizables o en evidencias compartidas, entonces desemboca en un intersubjetivismo disfrazado. Por ello, el objetivismo es una concepción de los valores que no me parece plausible y menos plausible todavía me parece el subjetivismo. Este suele traducirse en un relativismo axiológico y corre el riesgo de precipitarse en la propia disolución de los valores. Estas reservas me han llevado a optar por un modelo axiológico cifrado en una objetividad intersubjetiva. Esta preferencia, tal como tu sugieres, implica conjugar las premisas racionales y la corrección formal sobre las que debe establecerse el consenso, con la referencia a hechos y realidades, porque el consenso carecería de sentido si se limitara a operar en abstracto o en el vacío.

M. A.: Antes has hablado de una teoría pluralista en cuanto a las fuentes del Derecho. ¿Pero defiendes también -implica tu iusnaturalismo- una concepción pluralista del Derecho mismo, o sea, la idea de que el Derecho no se agota en el Derecho estatal y el Derecho internacional público en sentido clásico (el Derecho de los Estados)?

A.-E. P. L.: Una doctrina pluralista de las fuentes del Derecho, por estricta coherencia, precisa hallarse vertebrada sobre una teoría pluralista del ordenamiento jurídico. No parece ocioso recordar aquí que el pluralismo no es patrimonio teórico de los defensores del Derecho natural, ha sido y es defendido desde enfoques del todo ajenos al iusnaturalismo. Incluyo el pluralismo como un ingrediente de mi postura iusnaturalista, por considerar que se trata de un fenómeno actual que contradice e invalida algunos postulados básicos de la concepción más extendida e influyente del positivismo jurídico contemporáneo: la teoría pura del Derecho de Hans KELSEN.

Quienes desean mantener intacto el legado doctrinal de KELSEN, intentan mostrar el valor persistente de su teoría frente al «asedio» científico de determinadas concepciones contemporáneas, especialmente influyentes en los desarrollos de la teoría y la filosofía jurídica. Tengo para mí que esas alarmas y esa inquietud obsesiva por defender la teoría pura respecto a doctrinas y posturas teóricas y/o metodológicas sobre el Derecho responden a un error de enfoque. La teoría pura del Derecho elaborada por Hans KELSEN es un modelo de coherencia interna y, por tanto, resulta difícilmente atacable desde el interior de las premisas en las que se expresa su fundamento y desarrollo. Por eso, las doctrinas filosóficas y jurídicas que han cuestionado y cuestionan la teoría de KELSEN resultan poco eficaces y convincentes cuando pretenden desvirtuarla «desde dentro»; es decir, desde los propios postulados informadores de sus tesis y desde las inferencias que de ellos dimanan. 
Los herederos teóricos de KELSEN se hallan absortos en construir un baluarte especulativo capaz de resistir la confrontación intelectual con las concepciones jurídicas actuales, que reputan opuestas, como es el caso del iusnaturalismo, o revisionistas del legado científico del maestro vienés. Personalmente, no puedo convenir con lo que esa estrategia representa. A mi entender, el riesgo de impugnación o de revisión superadora de la teoría pura del Derecho no reside en las eventuales críticas que frente a ella directamente se avanzan, sino en las nuevas coordenadas a las que responden los sistemas jurídicos actuales y de las que las nuevas concepciones jurídicas se hacen cargo con mayor precisión y adecuación que el normativismo positivista kelseniano.

La teoría pura del Derecho se presentaba y justificaba a sí misma como una teoría formal, explicativa del Derecho positivo. Como quiera que el ordenamiento de los sistemas jurídicos de la sociedad global de nuestro tiempo han experimentado una importante transformación en su sistema de fuentes, así como en sus postulados fundamentadores, hoy se precisa de nuevos marcos teóricos y paradigmas metodológicos capaces de dar cuenta de esa nueva situación. El iusnaturalismo entiendo que es uno de los posibles cauces teóricos para hacerse cargo de los nuevos apremios que inciden en el significado actual del Derecho y de sus fuentes.

En algunos de mis trabajos he tratado de explicitar mi visión del pluralismo. Estimo que uno de los signos más relevantes de la coyuntura presente de los sistemas normativos y de sus fuentes en el constitucionalismo democrático ha sido el desplazamiento de su centro de gravedad desde el postulado de su carácter unitario al de su significado pluralista. Hoy se advierten una multiplicidad de centros de irradiación jurídica, en las sociedades multiculturales, complejas y abiertas de nuestro tiempo. Este fenómeno ha dado lugar a un pluralismo jurídico como signo del Derecho y de sus fuentes de producción normativa en el presente. Esta multiplicidad de facetas se traduce en una pluralidad de instancias creadoras de normas y se nutre de todo un amplio abanico de procedimientos formalmente bien diferenciados y con diferentes grados respecto de su efectividad.

Los ordenamientos jurídicos y, en especial, su sistema de fuentes, se han visto directamente afectados por el fenómeno del pluralismo. La superación del ámbito de referencia estatal, producto del nuevo orden de relaciones internacionales, se ha traducido en fuentes que expresan una supra estatalidad normativa (normas de organizaciones internacionales que se imponen a la soberanía estatal). Pero el desplazamiento del centro de gravedad en el proceso de determinación de las fuentes jurídicas no solo se ha producido por la aparición de poderes normativos superiores al Estado. De forma paralela, se ha realizado una ampliación de competencias normativas por parte de los entes sociales intermedios, situados entre el ciudadano y el poder estatal (entes territoriales, organizaciones sindicales...). Ahora se asiste a un fenómeno de infra estatalidad normativa, manifestado en el pluralismo de determinación de fuentes jurídicas. Para aludir a esa situación he utilizado la metáfora hidráulica del «Desbordamiento de las fuentes del Derecho».

El pluralismo jurídico se ha visto también potenciado por las repercusiones en el Derecho del fenómeno de la globalización. Parafraseando el título del libro de José ORTEGA Y GASSET, El tema de nuestro tiempo, podríamos decir que la globalización constituye hoy «el tema de nuestro tiempo», y también «el tema de nuestro espacio», puesto que habitamos en un mundo global. La ley estatal ha sido desplazada, en la 
sociedad global, por normas paccionadas y por usos consuetudinarios, que constituyen una de las más significativas manifestaciones de la globalización jurídica: la lex mercatoria. Debe advertirse que el término «lex» no evoca en esta denominación a la fuente jurídica procedente del Estado, sino al conjunto de reglas reguladoras de las transacciones financieras y comerciales debidas a los propios agentes mercantiles.

El nuevo Derecho de la sociedad global y, en particular, la lex mercatoria se diferencian del Derecho tradicional por:

- Su creación, pues el Derecho de ayer procedía, básicamente, del Estado, mientras que el nuevo Derecho, es creación de agencias e instituciones financieras, de sociedades y corporaciones multinacionales, que personifican a los «mercaderes» de nuestro tiempo.

- Su ámbito, que no se halla circunscrito o localizado en el espacio territorial estatal. El signo de la era global es precisamente la «deslocalización».

- Su estructura normativa, en la que la coacción ya no aparece, tal como ocurría en el Derecho del pasado, como un rasgo constitutivo de la ley estatal, con el que se quería garantizar su inexorable cumplimiento. La lex mercatoria, por el contrario, hace depender su cumplimiento de la adhesión voluntaria y otros medios de aplicación diferentes de la coacción estatal. Por ello, se designa a este nuevo Derecho como una versión blanda, «soft law», y «difusa» de juridicidad. Sobre este aspecto, denuncia Francisco LAPORTA la paradoja que entraña el que los problemas jurídicos que se derivan de la globalización en el orden internacional son «fuertes» mientras que las reglas jurídicas previstas para resolver esas cuestiones son «blandas».

Ha contribuido también al fenómeno de «deslegalización», es decir, a la superación del monopolio estatal de la juridicidad, el impacto de las Nuevas Tecnologías (NT) y de las Tecnologías de la Información y de la Comunicación (TIC) en el ámbito de la experiencia jurídica. La complejidad de la vida en las sociedades tecnológicamente desarrolladas impone el reconocimiento de regulaciones jurídicas dotadas de un alto grado de especialización. Como ejemplo reciente se puede aquí aludir a los denominados «códigos tipo» previstos en el art. 32 de la Ley Orgánica de Protección de Datos Personales 15/1999 consistentes en normas que pueden establecer los responsables de los ficheros públicos y privados para determinar pautas organizativas y funcionales uniformes, que abarquen aspectos básicos de su actividad, o aspectos instrumentales como la seguridad del entorno o de los programas y equipos.

De lo expuesto se desprende que el pluralismo jurídico ha condenado a la obsolescencia la imagen del ordenamiento jurídico, inferida de la concepción kelseniana, que evocaba la morfología de una pirámide o estructura piramidal, cuyo vértice venía constituido por la Grundnorm. Frente a esa representación, el actual significado de los sistemas jurídicos reclama una simbolización que se aproxima más a una bóveda que a una pirámide. Esa estructura abovedada implica la confluencia, involucro o interacción de un conjunto de redes, reglas y/o procedimientos normativos, procedentes de distintas instancias productoras de juridicidad. El actual desplazamiento, desde la unidad al pluralismo, induce y avala ese nuevo enfoque.

M. A.: ¿Cuáles serian los grandes nombres de la «versión bumanista y racionalista» del Derecho natural en la que tú te sitúas? ¿Y en qué autores estás pensando cuando te 
referías antes a las «versiones renovadoras del iusnaturalismo, abiertas a la historia, etc.? ¿Qué opinión tienes sobre el autor seguramente más influyente del iusnaturalismo contemporáneo, John FINNIS?

A.-E. P. L.: Me instas a explicitar los nombres de algunas de las figuras más destacadas en la tradición racionalista y humanista del Derecho natural. Sin ánimo de ser exhaustivo, pienso que los estoicos, y en particular CICERÓN, formularon algunas de las ideas fundamentadoras de un racionalismo y de un humanismo universalista y cosmopolita, que han sido punto de referencia a lo largo del desarrollo de la cultura occidental fiel a esos valores. En el ámbito del humanismo renacentista, esta tradición se hallará reformulada a través del pensamiento y la obra de diferentes figuras del periodo entre los que destacaría a ERASMO, Vives, Vitoria y LAS CASAS. Asimismo, en el seno de la Escuela del Derecho natural protestante, las doctrinas de GROCIO, PUFENDORF y LOCKE tendrán una importancia decisiva en el desarrollo de esa tradición cultural. Incumbe al iusnaturalismo racionalista ilustrado el haber culminado alguno de los aspectos básicos de esa trayectoria humanista y universalista. El movimiento ilustrado alcanzará su más notoria expresión en el pensamiento de KANT, cuya doctrina fue decisiva para la fundamentación moderna de los derechos humanos y para la propia génesis del Estado de Derecho. VICO jugará un papel determinante en el empeño por dotar de consciencia histórica a la reflexión iusnaturalista. Para ello, propuso conjugar el Derecho natural de los filósofos (referente al defendido por los racionalistas ilustrados), con el Derecho natural de las gentes, que se manifiesta y discurre en el tiempo.

Entre los autores renovadores del pensamiento iusnaturalista contemporáneo, estimo que debe citarse el nombre de Rudolf STAMMLER. Su célebre concepto del Derecho natural como idea constante de contenido variable propició eficazmente la reconciliación del iusnaturalismo con la historia. Lugar destacado en la renovación contemporánea del Derecho natural corresponde al último Gustav RADBRUCH, que con su reivindicación de un Derecho supralegal proporcionó motivos relevantes para la crítica de la positividad inicua. También su teoría sobre la naturaleza de las cosas, no exenta de controversias, propició la proyección del Derecho natural en distintos momentos y aspectos del ordenamiento jurídico. No puede soslayarse la importante contribución a clarificar el concepto del Derecho natural, llevada a cabo por Erik Wolf al analizar la multivocidad de sus versiones y, al propio tiempo, la univocidad de su función histórica. En sus obras de madurez, Luis RECASÉNS SICHES se propuso evidenciar la impronta iusnaturalista que informa los más importantes empeños actuales rehabilitadores de la racionalidad práctica, a la que denominó «logos de lo razonable». Ernst BLOCH tuvo el incuestionable acierto de recorrer los itinerarios del Derecho natural de inspiración progresista y emancipatoria de aquellos movimientos y autores más comprometidos con las conquistas de la sociedad democrática. Debe reconocerse a Guido FAssò su valiosa contribución a reconciliar el iusnaturalismo con la cultura contemporánea, sustituyendo la reflexión sobre el Derecho natural planteada sub specie aeternitatis, por su entendimiento sub specie historiae. No menos fértil debe juzgarse su iniciativa tendente a hacer transmigrar la hermenéutica de los valores que integran el contenido del Derecho natural, desde el firmamento de los ideales especulativos, al terrero de las experiencias jurídicas correctas. Incumbe a Lon FULLER el mérito de haber demostrado que la moral es el valor que hace posible el Derecho de las sociedades libres. Antonio 
TRUYOL Y SERRA, a partir de una concienzuda y brillante indagación historiográfica, ha mostrado la pervivencia de determinados valores y principios entroncados con el Derecho natural del pasado en la cultura jurídica y política del presente.

Solicitas mi opinión sobre el autor seguramente más influyente del iusnaturalismo contemporáneo, John FINNIS: entiendo que se trata de un pensador que ha contribuido a renovar el enfoque metodológico del Derecho natural, en cuanto que ha planteado su estudio desde premisas ligadas a la filosofía analítica. No obstante, esta innovación metódica no me parece que tiene correspondencia con su actitud respecto al contenido del Derecho natural. El concepto de naturaleza humana, del que FINNIS deriva los aspectos básicos de la prosperidad expresado por las exigencias de la razón práctica, que sirve de fundamento iusnaturalista de los valores, no es un concepto empírico, sino una noción metafísica. Por ello, no considera a la razón práctica como la fase última de la autoperfección, ni admite que sus principios deriven de un supuesto imperativo categórico en sentido kantiano, sino que los vincula a su necesaria participación en el plan divino. A partir de esas premisas, FINNIS reivindicará el carácter absoluto, inviolable y universal de las exigencias, que fundadas en el Derecho natural, se expresan en los derechos humanos, que constituyen la concreción de los valores jurídicos. Se halla extendida la opinión de que FINNIS, en su Natural Law and Natural Rights y otras publicaciones, ha propiciado una lectura en clave renovadora y actualizada de la doctrina iusnaturalista de Tomás DE AQUINO. Tengo para mí que es mucho más sugerente y prospectiva la visión que del aquinatense ofrece Guido FASSÒ en su libro: La legge della ragione. Por todo ello, sin pretender infravalorar la aportación iusnaturalista de FinNIS, debo reconocer que no es uno de mis autores de cabecera.

M. A.: Volvamos al plano biográfico. Después de tu paso por la Universidad de Salamanca, has sido, desde comienzos de los ochenta y hasta tu jubilación, profesor en la de Sevilla. Podríamos decir que abí ha transcurrido tu periodo de madurez. ¿Cómo resumirías esa etapa de tu vida académica? ¿Y por qué Sevilla?

A.-E. P. L.: Mi incorporación a la Universidad de Sevilla se produjo en noviembre de 1978 y, tal como indicas, desde esa fecha hasta la de mi jubilación he permanecido en ese destino académico. Mi estancia en la Universidad de Salamanca, como ya he tenido oportunidad de referir, fue muy grata, lo mismo en el plano intelectual que personal. De la convivencia académica de aquellos años surgieron unas relaciones de colaboración científica y amistad personal, conservadas y consolidadas en el tiempo. Mi vinculación con Salamanca se cimentaba, además, en una circunstancia muy relevante para mi vida personal. Allí conocí a mi mujer. Por estos motivos, de haber podido culminar mi carrera universitaria en Salamanca, es probable, que hubiese permanecido allí hasta mi jubilación.

En mi condición de profesor agregado, categoría docente hoy ya extinguida, realicé el preceptivo concurso de acceso a la cátedra y tuve la fortuna de obtener la plaza de Sevilla. El Tribunal que juzgó dicho concurso estuvo presidido por el profesor Joaquín RUIZ-GIMÉNEZ y se hallaba también integrado por los profesores Agustín DE Asís, José Delgado PinTo, Elías Díaz y Antonio Fernández-Galiano. Siempre he sentido la mayor admiración y afecto hacia esos profesores y me siento deudor de su pensamiento y de su ejemplo. 
En la Universidad de Sevilla ha transcurrido la mayor parte de mi vida académica, durante un periodo de cuarenta años, y en ella la he concluido. Durante más de treinta años mi labor investigadora y docente se desarrolló en el marco incomparable de la Antigua Fábrica de Tabacos. No puedo dejar de sentir cierto recuerdo nostálgico de aquellos ámbitos, la solemne austeridad de sus escalinatas, sus interminables pasillos, el silencio recoleto de sus patios en los que el tenue rumor del agua invitaban a la reflexión y al estudio. No puedo ocultar que el cambio de la sede de la Facultad de Derecho representó para mí un cierto declinar en el ámbito espacial del ejercicio de mi actividad universitaria. Reconozco, no obstante, que en el curso de la vida humana, en particular de la vida académica, más importante que los espacios físicos son las personas. Mi labor docente e investigadora se ha beneficiado de un grato clima de convivencia del que siempre he disfrutado en la Facultad de Derecho y en la Universidad.

No debo omitir el recuerdo emocionado de algunos maestros de la Facultad de Derecho de Sevilla, de cuya amistad he gozado. Guardo grata memoria del exquisito trato y sabia erudición del profesor Ignacio M. ${ }^{a}$ DE LOJENDIO E IRURE, en nuestro deambular por la Antigua Fábrica de Tabacos. Mantuve durante años una fecunda relación científica y la común inquietud por los problemas universitarios con los profesores Jaime García AÑoveros, Manuel Clavero Arévalo y José Martínez Gijón. Mis estudios en la temática de los derechos humanos son, en buena parte, deudores del estímulo, así como del pensamiento y la obra del profesor Juan Antonio CARRILLO SALCEDO, con quien mantuve siempre un fértil debate intelectual.

Al incorporarme a la Cátedra de Filosofía del Derecho de la Universidad de Sevilla, conté con la ayuda decidida y decisiva del entonces decano de la Facultad de Derecho, el profesor Miguel RODRÍGUEZ-PIÑERO Y BRAVO-FERRER, quien contribuyó eficazmente a facilitar mi aclimatación al mundo universitario y cultural hispalense. No puedo tampoco soslayar el magisterio jurídico constante recibido del profesor Manuel OlivenCia RuIZ, quien, desde la presidencia de esa «cátedra existencial» en que la Tertulia del Coliseo consiste, nos impartió a los contertulios una lección admirable de cultura cívica.

De mis compañeros universitarios hispalenses he hallado siempre esa libertad de espíritu que consiente el que cada uno haga lo que cree que debe hacer y deje hacerlo a lo demás. De los profesores que han prestado atención a mis trabajos, he recibido pertinentes observaciones valiosas y, en ocasiones, críticas, expresadas a menudo desde el gracejo y la ironía propias del talante intelectual sevillano. De los más afines, he recibido siempre el aliento, el estímulo y la colaboración que nos ayudan y nos incitan a seguir adelante.

Debo hacer especial mención a la excelente atmósfera de laboriosidad y cordialidad que siempre ha existido en el Departamento de Filosofía del Derecho del que formé parte. Algunos de sus integrantes nos han abandonado para siempre, pero nos han dejado la imperecedera memoria de su ejemplo; otros han culminado brillantemente su carrera académica en otros centros y quienes lo integran hoy constituyen un cabal paradigma de cuanto debe ser un docente y un investigador universitario.

Tengo, por tanto, que reconocer y agradecer, que en estas cuatro décadas he podido mantener relaciones de colaboración científica y, en definitiva, de amistad con un 
buen número de los miembros de la Facultad de Derecho y con todos los integrantes del Departamento de Filosofía del Derecho de la Universidad de Sevilla.

M. A.: Me gustaría abora que nos suministraras algo así como una guía de tu producción bibliográfica, que es muy abundante y comienza en 1969. ¿Cuáles consideras que son los títulos más significativos de tu producción iusfilosófica?

A.-E. P. L.: Aludes a que mi producción bibliográfica es muy abundante, yo diría que es excesiva. En el atardecer de la vida intelectual sentimos el deseo de hacer inventario de cuanto hemos escrito. Me he sentido abrumado al comprobar la cantidad de textos publicados, sabedor de que, en el ámbito de la cultura, suelen oponerse, siempre en favor de la primera, la calidad a la cantidad. Me temo hallarme incurso en el vicio de «grafomanía» que Rudolf VON IHERING atribuía a algunos profesores universitarios. Puedo alegar en mi descargo que, en muchas ocasiones, he sentido el deseo de plasmar por escrito mis principales inquietudes y estudios sobre diferentes cuestiones jurídicas. En otros casos, por la índole de los temas que he tratado, instituciones académicas y revistas me han solicitado colaboraciones, a las que he intentado atender, pues no hacerlo me hubiese parecido una actitud displicente.

El conjunto de mi producción bibliográfica estimo que puede agruparse en torno a cuatro bloques temáticos: el análisis sistemático del significado y alcance de la Filosofía y la Teoría del Derecho, así como la consideración de algunos de sus conceptos y categorías básicos; la contribución a la historia de la cultura jurídica, en sus distintos momentos y tendencias; el estudio del concepto y desarrollo de los derechos humanos, del Estado de Derecho y del constitucionalismo, con atención especial a algunos de los derechos fundamentales; la reflexión sobre el impacto de la Nuevas Tecnologías (NT) y de las Tecnologías de la Información y de la Comunicación (TIC) en la experiencia jurídica.

- Respecto a algunos de los títulos que pueden incluirse en el primer bloque temático, podría reseñar mis Lecciones de Filosofía del Derecho. Presupuestos para una filosofía de la experiencia jurídica, donde intento ofrecer mi punto de vista sobre esta disciplina, así como sobre sus principales problemas actuales. En la Teoría del derecho. Una concepción de la experiencia jurídica, obra elaborada con la colaboración de los profesores: Carlos AlARCÓn, Rafael GONZÁLEZ-TABLAS y Antonio RuIZ DE LA CuESTA, se abordan las cuestiones básicas que informan el saber jurídico, partiendo de una concepción de la experiencia jurídica vertebrada sobre un tetradimensionalismo, que implica asumir el Derecho en sus dimensiones social, normativa, axiológica y temporal. Se ocupan también de cuestiones abiertas en la teoría jurídica actual, mis libros sobre El desbordamiento de las fuentes del Derecho, al que ya me he referido anteriormente, y La seguridad jurídica. Este último libro se propuso dar cuenta de los nuevos rumbos por los que discurre la proyección jurídica de la seguridad como valor fundamental (Grundwert) de las sociedades democráticas actuales. Ello me llevó a revisar el concepto de la seguridad jurídica; su relevancia como elemento constitutivo del Estado de Derecho, así como su significado como valor fundamental de esa forma política, lo que obliga a reconsiderar su conexión con los demás valores, en particular, con la justicia.

- Entre mis contribuciones históricas, puedo hacer referencia a mi propia tesis doctoral boloñesa, publicada luego en España con el título Iusnaturalismo y positivis- 
mo jurídico en la Italia moderna en la que bajo el magisterio de Guido FASsÒ, traté de analizar los principales debates entre estas dos grandes tendencias de la filosofía jurídica, sustentadas por los principales iusfilósofos italianos. Coincidiendo con el Quinto Centenario del Descubrimiento, publiqué el libro, La polémica sobre el Nuevo Mundo. Los clásicos españoles de la Filosofía del Derecho, donde intenté recoger las controversias de nuestros clásicos con relación a las buenas y malas razones tendentes a legitimar la colonización americana. De esta obra, gracias al generoso impulso de Ernesto GARZÓN VALDÉS, se publicó una versión alemana. En el libro Trayectorias contemporáneas de la Filosofía y la Teoría del Derecho, tracé una síntesis de las principales escuelas, movimientos y autores de la cultura jurídica de nuestro tiempo. En la última edición de esta obra incluí un capítulo específicamente dedicado al pensamiento español y otro relativo a la doctrina latinoamericana.

En mi obra La Filosofía del Derecho en perspectiva histórica reuní diversos ensayos relativos al estudio del pensamiento de distintas figuras de la filosofía jurídica en un volumen. Atendí con ello a la razón esencial que los aunaba. Todos ellos pretendían contribuir a una aproximación sub specie bistoriae a la cultura jurídica. Cuando indagamos las construcciones teóricas debidas a figuras del pensamiento jurídico del pasado y del presente, advertimos sus aportaciones y sus límites y, por repercusión, vislumbramos las aportaciones y límites de nuestras propias tesis. De ahí, que la fecundidad de la historiografía del pensamiento jurídico resida en que, al estudiar las ideas de quienes nos precedieron, avanzamos en el conocimiento de nosotros mismos. Se produce aquí una situación similar a lo que en la teoría moderna de la interpretación se conoce como el «círculo hermenéutico». Quien estudia el pensamiento ajeno contribuye a rescatarlo del olvido, pero se nutre, al propio tiempo, de las experiencias e ideas del pensamiento estudiado. Hace tan solo unos meses se ha publicado mi último estudio historiográfico. Se trata del libro, Contribución a la bistoria de la cultura jurídica, integrado por unos estudios que, pese a la diversidad de sus argumentos, responden a una inquietud intelectual común: mostrar la indispensabilidad de la historia para la comprensión cabal de la Filosofía del Derecho y, en definitiva, de la cultura jurídica.

- Se incluye en mis estudios dedicados a las libertades, el Estado de Derecho y el constitucionalismo, el libro Derechos humanos, Estado de Derecho y Constitución, en cuyas páginas se intenta perfilar la delimitación conceptual de los derechos humanos, a partir de una aproximación sincrónica y diacrónica. Se analiza también en esta obra, el proceso de formación del Estado de Derecho, así como su estructura, funcionamiento y modalidades. La última parte del libro aborda las peculiaridades de los métodos de interpretación de las normas constitucionales y de los derechos fundamentales, al tiempo que se avanza un comentario sistemático de algunos de los derechos fundamentales proclamados en la Constitución española de 1978. El volumen monográfico Los derechos fundamentales, que forma parte de la colección «Temas clave de la Constitución española», trata de ofrecer una visión compendiada del concepto, fundamento y sistema de los derechos fundamentales reconocidos en nuestra Ley de leyes, así como de los instrumentos de tutela jurídica de los mismos. Fiel a su título, el libro Nuevos retos del Estado Constitucional: valores, derechos, garantías, incluido en los cuadernos «Democracia y Derechos Humanos», que dirige Isabel GARRIDO en la Universidad de Alcalá de Henares, estudia el nuevo horizonte del constitucionalismo, producto de la 
metamorfosis de los valores, derechos y los instrumentos de protección de las libertades, que ha tenido lugar en estas últimas décadas en las sociedades democráticas. El paradigma generacional de los derechos humanos constituyó el objeto temático de mi libro, La tercera generación de derechos bumanos, en dicha obra me propuse avanzar las buenas razones que justifican el enfoque generacional de los derechos y libertades.

Fruto de mi labor de investigación en el Max Planck Institut de Heidelberg, donde recibí valiosas orientaciones de Werner MORVAY, Fiedrich MÜLLER y Antonio TruYOL Y SERRA y desde donde pude desplazarme a otros destinos germanos en donde disfruté del estímulo intelectual de Ulrich KLUG y Ernesto GARZÓN VALDÉs, fue la publicación de mi libro Dimensiones de la igualdad, aparecido en los cuadernos del Instituto «Bartolomé de las Casas» de la Universidad Carlos III, dirigidos por Rafael DE Asís y Francisco Javier ANSUÁTEGUI. Esta obra fue acogida con cordial discrepancia por algunas colegas feministas, disconformes con mi crítica a la discriminación inversa. Debo puntualizar, al respecto, mi total conformidad con las acciones positivas y las políticas que tienden a la plena integración y emancipación de la mujer. Pero estimo, que allí donde existe una igualdad de oportunidades, real y efectiva, la discriminación inversa o positiva y los sistemas de cuotas pueden representar un atentado contra la propia dignidad de la mujer, al implicar un paternalismo que puede interpretarse como una aceptación implícita de la inferioridad femenina. Solo en aquellos casos en que subsisten, vergüenza da reconocer que son muchas, situaciones de marginación y discriminación de género, pueden ser legítimas la discriminación inversa y la política de cuotas. Pero se deberán considerar medidas excepcionales, destinadas a promover la efectividad de una igualdad de trato y oportunidades. En los demás casos, esas políticas representan una injustificada vulneración de la igualdad.

No descarto que esta actitud pueda hallarse influida por una vivencia personal. Durante la etapa en que fui decano de la Facultad de Derecho de Sevilla, participé como miembro del jurado de unos premios convocados por una entidad cultural y destinados a galardonar a los expedientes universitarios más destacados. Antes de proceder a nuestra decisión, una integrante del jurado comprometida con el feminismo, propuso que se estableciera una distribución paritaria, por razón de sexo, entre los concursantes. Los demás miembros del jurado nos opusimos a dicha propuesta, porque al no aparecer en las Bases de la Convocatoria, podría dar lugar a impugnaciones. Tras ponderar los méritos de los concursantes y la consiguiente deliberación, el jurado, por decisión unánime, concedió siete premios a alumnas y tres a los alumnos universitarios. Por lo que de haberse aceptado la propuesta de la feminista, se hubiera privado injustamente del premio a dos alumnas que lo merecían, para otorgarlo a dos alumnos cuyos méritos eran inferiores a los de aquellas.

- Se inscriben en mi producción científica relativa a los impactos de las NT y de las TIC en el Derecho, un ensayo monográfico publicado en la fecha, ahora ya lejana, de 1970 titulado Iuscibernética y metodología jurídica, al que siguió, algún año más tarde, el libro Cibernética, Informática y Derecho. Un análisis metodológico. Estos trabajos pioneros, como toda irrupción novedosa en el ámbito de la cultura jurídica, suscitaron la incomprensión de aquellos sectores de nuestra disciplina más apegados al tradicionalismo. En mis primeras oposiciones a la plaza de profesor agregado, incurrí en la ingenuidad de invocar como mérito académico el haberme ocupado de esta materia. Uno de los miem- 
bros del tribunal, en tono de conmiseración, me adujo que la cibernética y la informática eran unos fenómenos fruto de una moda pasajera y que esas categorías estaban destinadas a caer en el olvido poco tiempo después. Me alentó a que me ocupase de cuestiones de mayor entidad y con mayor proyección de futuro. Estimo que aquel profesor tenía adormecidas sus dotes de prospectiva y que, desde luego, no tenía cualidades de zahorí. Más tajante y hostil fue la actitud de quien presidía aquellos ejercicios académicos. En su opinión, ocuparse de esas proyecciones al Derecho, no solo representaba una pérdida de tiempo, sino que implicaban una ofensa a la dignidad de nuestra disciplina. Recordó que, desde Roma, el cultivo de la Jurisprudencia, como saber filosófico sobre el Derecho, entrañaba una forma de sacerdocio, que no podía degradarse al mundo materialista de las máquinas. Como es obvio, no obtuve plaza en esas oposiciones.

Algunos años más tarde, al iniciarse la década de los ochenta, por iniciativa del inolvidable Miguel SÁNCHEZ-MAZAS, se creó el Centro de Análisis, Lógica e Informática Jurídica (CALIJ), del que formamos parte tú y yo, así como el informático Ernesto GARCÍA CAMARERO. Entre las actividades promovidas por el CALIJ deben reseñarse los Encuentros o Congresos internacionales que tuvieron lugar en San Sebastián dirigido por el propio Miguel SÁNCHEZ-MAZAS, el que tú convocaste en Palma de Mallorca y el que me correspondió organizar en Sevilla. Estos eventos contribuyeron eficazmente a promover la reflexión colectiva sobre las implicaciones jurídicas de la informática en España y sería injusto soslayarlo. Conviene recordar que, en nuestro país, al igual que en Europa, fueron especialistas en Lógica y Filosofía del Derecho los primeros en estudiar las implicaciones jurídicas de las NT y las TIC. Hoy el interés por esta materia está presente en todas las ramas del Derecho.

En un clima más propicio a estas investigaciones, publique los libros: Nuevas tecnologías, sociedad y derecho. El impacto socio-jurídico de las $N$. T. de la información y Manual de informática y Derecho. Debo agradecer a la invitación de Francisco LAPORTA, en su etapa de director del Centro de Estudios Constitucionales, que dicha institución publicase el volumen: Libertad informática y leyes de protección de datos personales, en colaboración con Mario LOSANO y María F. GUERRERO MATEus. Por iniciativa y prologado por Vittorio FrosinI, se editó el libro: Saggi di informatica giuridica, en las publicaciones del Istituto di Informatica Giurídica de la Universidad La Sapienza de Roma, en el que había impartido cursos de doctorado. De esta obra existe una versión publicada en México bajo los auspicios de Ernesto GARZÓN VALDÉS y Rodolfo VÁZQUEZ.

En los últimos años, he sentido especial interés por la problemática que dimana de la ciberciudadanía y la teledemocracia, temas estudiados en mi libro: ¿Ciberciudadani@ociudadani@.com? En fecha más reciente, por invitación de Ernesto GARZÓN VALDÉs y en la Colección de monografías de la Fundación Coloquio Jurídico Europeo, publiqué un volumen colectivo sobre: Construcción europea y Teledemocracia, en colaboración con los profesores Francesc DE CARRERAS, Rafael GONZÁLEZ-TABLAS y Temis LIMBERGER. Esas cuestiones han sido también abordadas en el volumen sobre: Los derechos bumanos en la sociedad tecnológica.

M. A.: Hay una tesis a la que has hecho referencia de pasada, pero que para mí está entre las más interesantes de tu trabajo iusfilosófico; quiero pedirte por ello que nos des más detalles sobre la misma. Se trata de tu propuesta de fundamentar los derechos buma- 
nos combinando elementos de la teoría habermasiana de la verdad y del discurso con la filosofía de las necesidades básicas o radicales de la escuela de Budapest. ¿Podrías sintéticamente exponer los puntos fundamentales de tu planteamiento?

A.-E. P. L.: Mi tentativa de conjugar en la fundamentación de los derechos humanos la teoría habermasiana de la verdad con la teoría de las necesidades de Agnes HELLER puede parecer contradictoria, un intento de conciliar lo inconciliable. Pudiera creerse que se trata de establecer una conexión entre una teoría contrafáctica sobre los presupuestos ideales del discurso del consenso, con una teoría empírica, basada en hechos o datos antropológicos.

Entiendo que esta apreciación implicaría descuidar o desconocer circunstancias relevantes. Debe tenerse presente que HABERMAS, desde su obra Teoría y praxis, considera como un aspecto nuclear de su concepción la continuidad entre los marcos teóricos y la experiencia práctica, sin que admita una fractura entre la elaboración de sus tesis argumentativas y los presupuestos e implicaciones de las mismas en la praxis. Importa recordar que, para HABERMAS, el discurso intersubjetivo se concibe como «acción» comunicativa y que, para él, todo conocimiento, también el que dimana del discurso, persigue un interés; es conocimiento «interesado», en el sentido habermasiano (Erkennthis und Interesse). Podría, por tanto, haber elaborado mi teoría fundamentadora de los derechos apoyándome, de modo exclusivo, en las tesis de HABERMAS, ya que en ellas se fundamentan los derechos con la proyección de su argumentario teórico a la explicación de las reivindicaciones de la sociedad política en aras de su plena emancipación. Ese planteamiento me parece correcto, pero estimo que deja en la penumbra las raíces antropológicas de esas reivindicaciones.

Para responder a esa cuestión, me pareció más fértil acudir a la teoría de la Escuela de Budapest y, en concreto, a su formulación a través del pensamiento de Agnes HELLER. No estimo ocioso advertir la correlación entre las tesis de HABERMAS y HELLER. El primero elabora una teoría sobre las exigencias de corrección del discurso intersubjetvo, que posee una insoslayable vocación práctica. A su vez, Heller construye una teoría de las necesidades, que no consiste en una mera descripción de realidades fácticas, sino que representa una elaboración teórica de la propia noción de necesidad. Así, tomando como referencia el pensamiento de MARX, procede a distinguir entre: las necesidades naturales, referidas a los medios materiales indispensables para la autoconservación de la vida humana; las necesidades necesarias, no dirigidas a la mera supervivencia, en las cuales el elemento cultural, el moral y la costumbre son decisivos y cuya satisfacción es parte constitutiva de la vida normal de las personas pertenecientes a una determinada clase y a una determinada sociedad; y las necesidades radicales, que implican opciones axiológicas conscientes, que solo pueden ser satisfechas en una sociedad plenamente desalienada.

Agnes Heller acepta las reglas básicas de la teoría comunicativa de HABERMAS, de un discurso sin dominación como plena realización del ideal democrático. Le reprocha, no obstante, el limitarse a la dimensión racional de la comunicación, sin atender a la plenitud de las circunstancias antropológicas en las que esta se desenvuelve. Por este motivo, Agnes Heller diferencia el status dialógico de quien argumenta para que le sea satisfecha una necesidad y quien lo hace para aceptar o denegar esa petición, porque las circunstancias vitales de ambos supuestos son distintas. 
Por último, last but not least, conviene no olvidar que la Escuela de Francfort y la Escuela de Budapest representan dos manifestaciones de una interpretación del marxismo, de carácter humanista, antidogmático y democrático.

He insistido en la compatibilidad entre ambas teorías, para la fundamentación de los derechos, por entender que era el aspecto que podía suscitar mayores reservas y objeciones a mi propuesta. En definitiva, atendiendo a la necesidad de síntesis a que aludes en tu pregunta, estimo que las tesis de HABERMAS y HELLER no son incompatibles, sino complementarias y que ambas permiten una adecuada fundamentación de los derechos humanos.

He abogado por el intersubjetivismo axiológico porque esta actitud parte de la posibilidad de llegar a establecer las condiciones que permiten a la racionalidad práctica llegar a un cierto consenso abierto y revisable, sobre el fundamento de los derechos humanos. Pero cualquier concepción o fundamentación de los derechos humanos no puede quedar reducida a una serie de argumentaciones formales o procedimientos dialógicos, por grande que sea su elaboración y depuración discursiva. Pienso que en esta esfera, más que en cualquier otra, no se puede perder de vista la referencia inmediata de bumanidad que constituye la razón de ser de cualquier derecho y, por antonomasia, de los derechos humanos. De ahí, que el consenso al que apelo, lejos de traducirse en fórmulas abstractas y vacías, recibe su contenido material del sistema de necesidades básicas o radicales, que constituye su indeclinable soporte antropológico.

La teoría habermasiana proporciona, por tanto, el marco metódico, las condiciones ideales a que debe someterse el discurso racional fundamentador de los valores, así como a contrario sensu denuncia los factores que en las sociedades históricas distorsionan o impiden la posibilidad de llegar a legitimaciones racionales de los valores generalizables o universalizables en cuanto dotadas de «objetividad intersubjetiva».

Por su parte, la tesis de HELLER ha aportado datos relevantes sobre las condiciones antropológicas, sobre las exigencias o necesidades de la naturaleza humana que constituyen la base material de todo valor. Mérito destacable de esta teoría es su virtualidad para captar el entero desenvolvimiento de las necesidades y de su progresiva densidad axiológica, desde su fase elemental, ligada a la garantía de la subsistencia, a su dimensión superior, que permite el pleno desarrollo de la personalidad humana. Este planteamiento posee inmediata relevancia para fundamentar los distintos tipos y modalidades de derechos humanos.

M. A.: Volvamos de nuevo a tu trayectoria intelectual. ¿Qué cambios ha habido en tu manera de entender la filosofía del Derecho y los problemas iusfilosóficos? ¿Podríamos decir que toda tu obra obedece básicamente a un mismo proyecto intelectual trazado en los primeros años, en tu época de formación? ¿O hay algún cambio de orientación que consideres significativo?

A.-E. P. L.: Al iniciar la respuesta a esta pregunta, me inquieta, tras haber rememorado ese itinerario bibliográfico, que la dispersión de los temas tratados pueda implicar una discontinuidad o una cierta fractura epistemológica en mi actitud y planteamientos.

Un lúcido ensayo de crítica literaria, debido a José ORTEGA Y GASSET, lleva por título, revelador: Pio Baroja, anatomía de un alma dispersa. Ortega reconocía la amplitud 
y variedad temática de la obra de BAROJA. Pero, al mismo tiempo, denunciaba la falta de unidad interna de la inspiración y propósito de la exuberante producción narrativa barojiana.

$\mathrm{Al}$ hacer inventario y balance, en las páginas que anteceden, de lo que ha sido mi labor investigadora a lo largo de mi trayectoria universitaria, me asedia la inquietud de hallarme incurso en un análogo vicio de dispersión. En la serie de publicaciones que integran mi actividad investigadora, me he ocupado, simultánea o sucesivamente, de temas, en apariencia, muy dispares. El repaso retrospectivo de esas investigaciones, y de la multiplicidad de argumentos en ellas abordadas, me hace cuestionar si en las mismas se ha operado un cambio sensible en las ideas sustentadas, al haber estudiado temas tan heterogéneos que hacen inviable cualquier propósito sistematizador. Puede comprobarse, sin embargo, al considerar el conjunto de trabajos en que se ha concretado mi labor investigadora, que no me he alejado mucho de las posiciones de partida. He insistido desde las propias conclusiones de mi tesis boloñesa (1969, publicada en 1971) en la necesidad de que la reflexión filosófica sobre el Derecho se halle conscientemente comprometida con la garantía democrática de los valores de la paz, la igualdad, la tolerancia y la libertad. Entonces pensaba (y ahora también) que el iusnaturalismo ha sido y es un cauce teórico para propiciar tal reflexión. Este planteamiento, para no ser confundido con una recaída en el orden de los principios metafísicos, ahistóricos, eternos e inmutables, obligaba a explicitar su sentido. Para ello, frente a cualquiera de sus versiones dogmáticas, he propugnado un iusnaturalismo radicalmente crítico, recuperando el legado de su mejor función histórica emancipatoria, es decir, su contribución al establecimiento de un límite crítico-racional al arbitrio de quien detenta el poder. Dicha opción consiguientemente exige emprender una tarea de sociología cultural tendente a denunciar la función ideológica de determinadas versiones de un sedicente iusnaturalismo, tras cuyas declaraciones retóricas en favor del Derecho natural se ampara una actitud metódica exegético-positivista, que desemboca en el culto incondicionado de la legalidad. En definitiva, mi adhesión al iusnaturalismo ha sido siempre más problemática que dogmática, lo que me ha permitido estar siempre abierto a influencias y teorías que, en distintos momentos de mi vida intelectual, han contribuido a perfilar mejor mis propias tesis. Estimo también que muchas de las incomprensiones y malentendidos sobre el Derecho natural, en particular en lo referente a la doctrina de los clásicos, proceden de un anacronismo hermenéutico, que ha llevado a considerar como postulados absolutos y eternos lo que eran respuestas oportunas a determinados problemas de un determinado tiempo y un determinado lugar. Dicho enfoque ha contribuido a ofuscar, en muchas ocasiones, aquellas ideas de los clásicos dotadas de vocación de futuro.

En mi juventud, como otros muchos universitarios de mi generación, me sentí atraído por la literatura marxista. Fui ávido lector de algunas de las obras de MARX y ENGELS, en particular de sus escritos más relacionados con la filosofía jurídica y política, así como de la bibliografía más relevante de la Escuela de Frankfort y de la Escuela de Budapest. Nunca fui marxista de estricta observancia, pero esos enfoques me sirvieron para comprender la ineludible dimensión social del Derecho, sus presupuestos ideológicos, el tránsito desde las libertades individuales a los derechos económicos y sociales... En años sucesivos, el conocimiento de determinados sucesos y mis viajes por 
la Europa del Este, me han llevado a cuestionar las virtualidades emancipatorias del denominado «socialismo real». En todo caso, estimo que sin la crítica marxista a las contradicciones del capitalismo y de la sociedad burguesa, no hubieran sido posibles muchas de las conquistas sociales que hoy se consideran irrenunciables en las sociedades democráticas. En mi ensayo sobre El puesto de Marx en la Historia de los derechos bumanos, incluido ahora en mi volumen La Filosofía del Derecho en perspectiva históri$c a$, trazo una exposición y balance de mi actitud en esta materia.

Pienso que tampoco ha existido discontinuidad en mis estudios sobre las repercusiones tecnológicas en el Derecho. Desde mis primeros trabajos, creo haber sido consciente de la ambivalencia que resulta de la proyección de las NT y las TIC a la experiencia jurídica. En muchos aspectos, han propiciado innegables avances en los procesos de documentación y gestión del Derecho, así como a un perfeccionamiento de los presupuestos lógicos y de las actividades de interpretación y aplicación de las normas. También la tecnología ha permitido renovar determinados cauces del control político (cibertransparencia) y de la participación cívica (ciberciudadania y teledemocracia), pero siempre fui consciente del riesgo liberticida de determinados abusos en la utilización de las NT y las TIC. Nunca me ha abandonado el interés por estas cuestiones. Para corroborarlo indicaré que por invitación de Tomas DE LA QUADRA SALCEDO, director del Proyecto El Derecho en la Era Digital, he dedicado estos últimos meses a la reflexión de un tema que me apasiona: el desafío que para los derechos humanos y para las propias sociedades libres representan determinados progresos de la tecnociencia y, en concreto, las tesis que sobre este fenómeno se están planteando desde las posturas transhumanistas y poshumanistas.

Pese haber transcurrido ya algún tiempo desde la fecha de mi jubilación, mantengo viva mi inquietud cultural, porque el universitario es un intelectual y para un intelectual que ha asumido la máxima de Max WEBER de Wissenschaft als Beruf, la tarea científica nunca acaba; es, por decirlo con las palabras con que Karl POPPER tituló su autobiografía, una «búsqueda sin término».

En resumen, estimo que pese a la aparente dispersión y heterogeneidad de los temas abordados en mis publicaciones, su motivación principal ha sido unívoca: contribuir, desde perspectivas históricas y sistemáticas, a la tarea de clarificación, elaboración y fundamentación de los valores y derechos que deben informar la experiencia jurídica y política.

M. A.: Acabo de leer el trabajo que acabas de mencionar y que lleva como título «Las generaciones de derechos ante el desafío posthumanista». Abí haces referencia al carácter ideológico de ese movimiento y sostienes incluso que el llamado «posthumanismo»o «transhumanismo» constituye, en tu opinión, un antibumanismo; en concreto, hacia el final del trabajo afirmas literalmente que «el posthumanismo, por tanto, entraña un antibumanismo». ¿Podrías clarificar eso para el lector de Doxa, que quizá haya recibido el impacto de la lectura de la reciente obra de HARARI, Homo Deus?

A.-E. P. L.: En principio, deseo puntualizar que las expresiones «transhumanismo» y «posthumanismo» designan a movimientos de la ciencia y de la cultura de nuestro tiempo. En numerosas ocasiones, estos términos son asumidos y empleados de forma indistinta, como sinónimos. Ambas expresiones aluden a la reivindicación 
del derecho a investigar y utilizar, con plena libertad, los avances de la tecnociencia, para conseguir la mejora o potenciación de las capacidades físicas y mentales de las personas. Al propio tiempo, estos movimientos se proponen transcender los límites naturales, biológicos o sociales que actualmente condicionan el pleno desarrollo de la existencia. Ahora bien, desde algunos enfoques teóricos, se establece una diferencia básica entre estos dos términos. Se indica, así, que mientras los transhumanistas sostienen que la tecnociencia debe contribuir a la mejora, pero no a la suplantación, de la especie humana, los posthumanistas postulan la superación de la humanidad actual por una superhumanidad, como resultado final del proceso de desarrollo tecnocientífico.

Las tesis poshumanistas, y en ello la obra de Yuval Noah Harari, Homo Deus, es un ejemplo elocuente, rechazan que puedan ser consideradas como utopías, profecías o elucubraciones sobre el futuro. Reivindican su carácter de teorías que reflejan el statu quo actual de la tecnociencia y su desarrollo inmediato. Se presentan con la pretensión de estricta objetividad, neutralidad y asepsia.

Las teorías posthumanistas se manifiestan como un conjunto de tesis e ideas irrefutables, avaladas por los desarrollos de la ciencia y la tecnología. Hace ya algunos años, Jürgen HABERMAS en su lúcida obra: Ciencia y técnica como ideología, denunció la pretensión tecnocrática de presentar determinado tipo de conocimientos y propuestas, sedicentemente tecnocientíficos, cuando en realidad ocultan opciones prácticas e intereses. La ideología tecnocrática trata de sustraer al debate científico y político particulares intereses, presentados como teorías, cuando en realidad suponen meras propuestas ideológicas.

Los principales argumentos posthumanistas se plantean hoy como verdades tecnocientíficas irrefutables e inexorables. No obstante, un análisis crítico de esas propuestas revela que ese discurso responde a la pretensión ideológica de escamotear las grandes elecciones y decisiones sobre el presente y el futuro de la condición humana y del desarrollo tecnológico al debate político. Tiene razón Stefano RoDOTÀ cuando se pregunta si las transformaciones previstas y auspiciadas por el posthumanismo, se plantean en nombre del beneficio económico o del interés de las personas. Para responder estos retos, que afectan a la humanidad en su conjunto, no debe acudirse a la inteligencia artificial, sino a las opciones de la sociedad política.

El carácter ideológico de las propuestas posthumanistas se evidencia también cuando, a través de ellas, se propugna expropiar de la decisión colectiva ética y política, las cuestiones vitales de toda sociedad, como la educación, la sanidad o la pobreza. Los poderes que apoyan y financian la investigación tecnocientífica, no son anónimos, se trata de personas, entidades o corporaciones reales y concretas, con intereses e ideologías fácilmente comprobables, que no pueden eludir su responsabilidad social y política.

Resulta, al propio tiempo, necesario clarificar el sentido del prefijo «post», que se incluye en la expresión «posthumanismo». Dicho prefijo puede asumir dos significados diferentes: puede aludir a la sucesión cronológica o al perfeccionamiento de las concepciones o movimientos que le preceden; o bien, expresar la abolición de los mismos. El posthumanismo, asume la segunda acepción indicada. Por ello, el posthumanismo no implica la mejora de la tradición humanista, sino que supone su negación, 
abolición o suplantación. El posthumanismo, por tanto, entraña un antihumanismo, por lo que postular unos derechos humanos antihumanistas implica una evidente contradictio in terminis. Si se parte de esta premisa, resulta evidente que no puede aludirse a la aparición de nuevos derechos procedentes del posthumanismo, ya que esta ideología representa, precisamente, la negación de la cultura humanista.

El carácter ideológico de las tesis posthumanistas se evidencia, asimismo, en su pretensión de reputar al humanismo como una experiencia cultural periclitada y conclusa. Desde las premisas posthumanistas se pretende desconocer que el proyecto jurídico-político humanista es todavía una promesa incumplida para amplios sectores de nuestro mundo, que no se han emancipado de la ignorancia, del hambre o de la opresión. Se produce así la situación paradójica de que, mientras se está reclamando un proyecto posthumanista, grandes sectores de la población mundial se hallan condenados a una condición de infrahumanidad.

No creo aventurado conjeturar que, en nuestro inmediato futuro, el discurso posthumanista se hallará en el núcleo del debate científico, económico, social, cultural, ético y jurídico-político. Pienso, en definitiva, que para responder adecuadamente a esos nuevos retos, convendría tener presente la lúcida advertencia de Jürgen HABERMAS a tenor de la cual: «Al desafío de la técnica, no se le puede responder solo con la técnica».

M. A.: Tu último libro creo que es el titulado «Contribución a la bistoria de la cultura jurídica», publicado en 2017 y al que anteriormente has hecho una breve referencia indicando que, a pesar de la variedad de temas que incluye, su propósito central es el de mostrar la importancia que tiene la bistoria para comprender la cultura jurídica. Un aspecto importante de esa cultura, qué duda cabe, es la contraposición entre iusnaturalismo y positivismo jurídico, de la que ya hemos hablado en esta entrevista. En el libro, hay un breve capitulo dedicado a JHERING (a propósito de una reciente obra sobre el autor alemán debida a Luis LLOREDO) en el que, de alguna forma, vienes a sugerir que, en su etapa madura, no podría considerársele ya como un autor positivista. Y aqui es donde viene mi petición de aclaración. Pues no me ha quedado claro si tu interpretación del «segundo JHERING» significa considerarlo como un autor iusnaturalista (el último apartado de ese capitulo se titula «Conclusión: JHERING desde el positivismo jurídico al iusnaturalismo»; y en el mismo puede leerse que KELSEN «no dudó en adscribir al JHERING maduro al ámbito del paradigma que supone la más irreductible antítesis del iuspositivismo: el iusnaturalismo»; pero tú no dices explícitamente que JHERING baya sido un iusnaturalista); o simplemente como un iuspositivista de un tipo peculiar (y de abi la crítica que formulas al, por lo demás, muy elogioso comentario que haces al libro de LLOREDO: no se puede hablar de «paradigma positivista», porque habria «una pluralidad de paradigmas positivistas»). No te oculto que mi interés por formularte esta pregunta tiene que ver con mi convicción de que JHERING es el principal precursor de lo que boy suele llamarse «postpositivismo»; y también con mi idea de que la razón fundamental para no ser boy iuspositivista (tampoco iusnaturalista) es de carácter histórico. O sea, los cambios que han tenido lugar en nuestros Derechos (primero, la positivización del Derecho, y luego —en las últimas décadas - la constitucionalización del Derecho) ban becho que la contraposición clásica entre iusnaturalismo y positivismo jurídico baya perdido sentido en nuestros días. ¿Qué piensas sobre eso? Aunque supongo que tú plantearías el problema más bien 
en términos de contraposición entre diversos tipos de positivismos jurídicos y diversos tipos de iusnaturalismos. ¿Es así?

A.-E. P. L.: En relación con lo que planteas respecto a la postura doctrinal de JHERING, estimo que este evolucionó desde el formalismo y el conceptualismo, a partir de los que elabora su concepción de la Dogmática jurídica y en el que transcurre la primera etapa de su doctrina, hacia una posición de madurez, caracterizada por presupuestos teóricos y metodológicos que representaban, no solo el alejamiento, sino la abierta antítesis de sus posiciones científicas iniciales. Se produjo, en esta segunda etapa de su itinerario intelectual, un desplazamiento hacia posiciones jurídicas de signo abiertamente antiformalista. En esa fase, JHERING, se convierte en el principal inspirador y artífice del movimiento teleológico y de la jurisprudencia de intereses, así como de la proyección de la mentalidad sociológica al Derecho.

Al concluir el estudio al que haces referencia, es cierto que aludo al giro teórico de JHERING desde el positivismo jurídico al iusnaturalismo. Conviene recordar que, en la última etapa de la trayectoria intelectual de JHERING, su concepción del método de la ciencia jurídica tenderá a cuestionar, de manera abierta y concluyente, el positivismo jurídico expresado a través de los métodos dogmáticos, conceptualistas y formalistas del Derecho. En ella, afirma su convicción de que el origen de todo el Derecho es el fin, y que no existe ninguna proposición jurídica que no parta de un fin, o sea, de un motivo práctico. Conviene advertir, que los fines y necesidades en los que el Derecho se explicita, no son solo de carácter pragmático, sino también valores éticos. JHERING sostuvo, en su madurez, que, por encima del puro elemento formal de la lógica jurídica, existe, como algo más elevado y supremo, la idea sustancial de la justicia y de la moralidad. Esa decantación teórica motivó que Hans KELSEN, el más genuino defensor del positivismo jurídico en el siglo XX, pudiera calificar al JHERING maduro de iusnaturalista, por su invocación de valores éticos como elementos constitutivos del Derecho.

Pienso que la adscripción de JHERING, al iusnaturalismo no resulta infundada, aunque debo reconocer que él no se calificó de iusnaturalista, ni concibió expresamente su doctrina como una teoría del Derecho natural. Es normal que así fuera, si se tiene presente que las doctrinas iusnaturalistas predominantes en la cultura germana del tiempo de JHERING eran de orientación idealista y suprahistórica, lo que no se avenía con los fundamentos empíricos y sociologistas de la Jurisprudencia de intereses.

Ello no obsta para que se pueda considerar a JHERING como un precursor de nuevas tendencias iusnaturalistas, por idénticas razones por las que tú le consideras precursor del postpositivismo. Estimo que entre las posturas neoiusnaturalistas y el postpositivismo existe un terreno de encuentro, que permite superar la radicalidad de la tensión entre lo que Norberto BовBіo denominó: fratelli nenici, o sea, entre las versiones tradicionales del iusnaturalismo y el positivismo jurídico.

En el capítulo de tu libro Filosofía del Derecho y transformación social, bajo el rótulo de: «Ni positivismo jurídico ni neoconstitucionalismo: una defensa del constitucionalismo postpositivista», enumeras unas notas definitorias de tu concepción postpositivista: Constitucionalista; no positivista; basada en la unidad de la razón práctica, lo que supone negar que pueda trazarse una separación tajante (en el plano conceptual) entre el Derecho y la moral; defensora de un objetivismo moral mínimo; reconoce la impor- 
tancia de los principios y de la ponderación, así como el papel activo de la jurisdicción y subraya el carácter argumentativo del Derecho. Estos caracteres pueden ser suscritos por cualquier neoiusnaturalista, con leves observaciones de matiz. Quizá la diferencia actual entre neoiusnaturalismo y postpositivismo estriba, no tanto en los rasgos que ambas tendencias consideran como informadores del Derecho, sino en la forma de entenderlos; existe un acuerdo básico sobre los caracteres del orden jurídico, la diferencia se sitúa en el «porqué» de esos rasgos o caracteres. Así, por ejemplo, cuando el neoiusnaturalismo postula como característica del orden jurídico actual el constitucionalismo, lo hace porque esa orientación permite que los valores, principios y derechos que entrañan la proyección de la justicia y la moral al Derecho, se sitúen en la cúspide legitimadora de los Estados de Derecho. La Grundnorm, del sistema jurídico tendría un inequívoco significado moral, lo que equivaldría a instaurar el Derecho natural como fundamento legitimador del orden jurídico. En cambio, el postpositivismo, cuando acoge el constitucionalismo, lo hace por considerar que gracias a ese enfoque los valores, principios y derechos adquieren un status positivo y esa positivización permite otorgarles fuerza normativa y garantizar su eficaz tutela jurisdiccional, evitando que queden relegados a meras normas programáticas. De igual modo, cuando el neoiusnaturalismo defiende la actividad judicial, pretende posibilitar que los postulados de justicia y moralidad se integren en la interpretación y aplicación del Derecho. Para el postpositivismo, en cambio, esa facultad judicial se hallará encaminada al logro de la plenitud del orden jurídico y a la garantía eficaz de los derechos fundamentales. Por lo demás, esta diferencia de enfoques no los hace incompatibles, ni mutuamente excluyentes.

Afirmas en tu pregunta que la contraposición clásica entre iusnaturalismo y positivismo jurídico ha perdido sentido en nuestros días. Se trata de una tesis sustentada hoy por una amplia mayoría de filósofos del Derecho. No me siento inclinado a suscribir esa opinión que, como apuntas y se desprende de mis respuestas a preguntas anteriores, estimo que habría que matizar especificando a qué iusnaturalismos o iuspositivismos nos estamos refiriendo. Es bien conocida la tesis avanzada por Heinrich ROMMEN sobre el «eterno retorno» del Derecho natural, para aludir a que, tras las etapas de estricto formalismo, abstinencia de valores y experiencias de ilegitimidad política generadoras de legalidad inicua, se tiende a volver a fundamentar el Derecho en postulados de justicia y a establecer como su finalidad la consecución de determinadas pautas de moralidad. La referencia a esta idea trae a mi memoria una circunstancia anecdótica. Quien fue en vida leal amigo y con quien compartí inquietudes universitarias, Gregorio PECES-BARBA, gustaba de provocarme (nunca lo consiguió), diciéndome que la tesis del «eterno retorno» del Derecho natural, le evocaba la imagen de esas películas de terror en las que el monstruo parece que ha muerto, pero revive una y otra vez... No habré de insistir en que no comparto esa tétrica metáfora. Por contra, estimo que también se da un «eterno retorno» del positivismo jurídico, como contrapunto a excesos antiformalistas y a determinados ataques al imperio de la ley y contra la seguridad jurídica en sociedades democráticas. En suma, soy de la opinión de que existe una sucesión cíclica entre los dos fratelli nenici, que se produce a través de reformulaciones y revisiones presentadas bajo la forma de nuevas adjetivaciones o prefijos.

M. A.: Hemos pasado revista en esta entrevista a tu trayectoria académica, a tu concepción de la filosofía del Derecho en general y a algunas tesis más específicas que has de- 
fendido en ese campo teórico. Pero abora quiero pasar a una cuestión más práctica, o sea, a preguntarte de qué manera ese neoiusnaturalismo que defiendes se proyecta en relación con la praxis social y, en particular, con la politica. Ya antes nos has dicho algo en relación con el posthumanismo y con las amenazas que boy se ciernen sobre los derechos bumanos, procedentes de las nuevas tecnologías, pero ahora quisiera que expusieras tu opinión sobre el tema que, casi podría decirse, ha monopolizado la discusión política en España en los últimos meses (o quizá ya años): el del nacionalismo. Dado que conozco lo que piensas al respecto, pues, aparte de conversaciones que hemos tenido recientemente, he podido leer también un texto tuyo sobre el particular, quisiera concretar así la pregunta: ¿Cuáles son los elementos de irracionalismo y de totalitarismo que ves en los nacionalismos? ¿Se pueden aplicar a todos los tipos de nacionalismos? ¿Qué distingue al «patriotismo nacionalista» del «patriotismo constitucionalista»?

A.-E. P. L.: Soy de la opinión de que el nacionalismo político representa una radical negación de los valores, de las pautas institucionales y de los derechos que conforman las sociedades libres y los Estados de Derecho. Apoyo esta apreciación en dos características del nacionalismo que, como anticipas en tu pregunta, me parecen inherentes a su significado y modus operandi. Se trata de su designio tendente a sustraer la acción política del ámbito de la racionalidad, para situarla en el plano de las emociones y los sentimientos; y en su concepción totalitaria y transpersonalista de la comunidad política. Intentaré explicitar, por aproximación sucesiva, estos dos elementos constitutivos de la ideología nacionalista.

Debemos a Friedrich NiETzSCHE el haber distinguido, en su obra Orígenes de la tragedia, dos actitudes básicas del comportamiento humano. Al estudiar, en dicha obra, la génesis del teatro en la Grecia clásica y a partir de una brillante recreación de la mitología helena, distingue dos actitudes, que respectivamente denomina: espíritu dionisíaco y espíritu apolíneo. El primero, dimana del culto orgiástico a Dionisio, mientras que el segundo parte del culto estético a Apolo. El espíritu dionisíaco representa una reminiscencia y perpetuación de la comunidad tribal, en la que el individuo se halla absorbido por la colectividad y, por eso, se manifiesta en todas las expresiones sociales en las que prevalece el vínculo de pertenencia al grupo. Dicho espíritu se exterioriza a través de las emociones, los sentimientos, las pasiones, y las pulsiones irreflexivas, que se consideran como fuerzas motrices de la convivencia. Por contra, el espíritu apolíneo reivindica el valor de la individualidad, de la persona como ente libre y autónomo. Recuérdese que, para SÓCRATES, la persona posee un valor universal. Este espíritu se expresará a través de la razón, del pensamiento lógico, de la ironía y de la estética.

NiETZSCHE lamenta que, en la trayectoria cultural y política de Occidente, de modo especial por el influjo de la filosofía del Renacimiento y de la Ilustración, el espíritu dionisíaco se haya visto progresivamente desplazado por el espíritu apolíneo. En relación con esta tesis, yo no puedo estar más en desacuerdo con el filósofo germano, porque, como se desprende del notorio análisis desarrollado por György LUKÀCS en su libro El asalto a la razón, la exaltación de la irracionalidad en la doctrina nietzscheana, fue uno de los ingredientes que contribuyeron a conformar la ideología nazi.

Debo aclarar que el espíritu dionisíaco subsiste hoy en numerosas manifestaciones de la vida colectiva, de modo plenamente legítimo. Así, se revela a través de diversas formas lúdicas, artísticas, en las fiestas, en el deporte... El riesgo surge, cuando el es- 
píritu dionisíaco se convierte en mecanismo de actuación política y como ocurre en la ideología nacionalista, ese espíritu es controlado y manipulado para la obtención de objetivos políticos. Cuando en la vida política la deliberación racional es suplantada por las pasiones y los sentimientos, queda expedito el camino hacia la barbarie.

$\mathrm{El}$ otro elemento constitutivo del nacionalismo político, que me parece inaceptable, es su concepción de la comunidad política como una entidad totalitaria. Asumiendo la terminología de Karl POPPER, el nacionalismo aparecería como una doctrina que concibe la sociedad como un ente holístico, como una totalidad cerrada, opuesta a la libertad y autonomía de las personas, que son elementos básicos de las sociedades abiertas. Mientras que en una sociedad libre y democrática, la comunidad política es el resultado de las acciones, intereses y el ejercicio de los derechos de las personas que la integran, para el nacionalismo político la Nación es un ente dotado de personalidad propia y cuyos intereses trascienden y se sobreponen a los de los individuos que la componen. Ello implica una manifestación evidente de transpersonalismo.

Por su inequívoca vocación totalitaria, el nacionalismo pretende absorber, controlar y manipular todas las relaciones de la sociedad civil y política. Para ello, convertirá el aprendizaje escolar en adoctrinamiento y a los medios de comunicación, en medios de propaganda. No huelga recordar que, en la Alemania nazi, Joseph Goebbels no era ministro de Información, sino que, sin concesión alguna al pudor, ostentaba el Ministerio de la Propaganda.

Es práctica habitual de todo nacionalismo político el crear enemigos, no importa si reales o ficticios, a los que se les atribuyen todos los agravios y males que pesan sobre la colectividad. Son los enemigos de la nación que aparecen bajo la consabida imagen del «chivo expiatorio». A partir de esa falacia política el nacionalismo pretende garantizar el fervor y el fanatismo de las masas, asegurando su fidelidad a las fantasías patrióticas de la mitología nacionalista.

Hanah ARENDT, en su célebre estudio sobre Orígenes del totalitarismo, ha denunciado, de manera clarividente, la génesis, desarrollo e implantación de estos mecanismos envilecedores de la política por parte de las sociedades totalitarias.

El nacionalismo político contemporáneo se ha nutrido también de dos célebres concepciones de la filosofía política: la teoría de la razón de Estado y la doctrina de Volksgeist. Esta última, tuvo su origen en formulaciones debidas al historicismo, el idealismo y el romanticismo germanos. Ese mito del «espíritu del pueblo» consiste en la pretensión de que las entidades colectivas, es decir, los pueblos, poseen una identidad propia y que, por ese motivo, se hallan dotadas de una personalidad, una voluntad y unas metas y un destino genuinos y peculiares, que las distinguen de cualquier otra formación social. La falacia de esta pretensión se demuestra cuando ese pretendido «espíritu del pueblo» tiene que expresar sus designios. Entonces, se hace preciso que tal espíritu se revele a través de personas individuales y concretas, cuyas ideas son hipostasiadas como procedentes de un ente colectivo que no puede expresarlas, porque no existe.

Los políticos nacionalistas se sirven de ese mito para, en su nombre, atribuirse la representación de todo un pueblo, considerado como una unidad omnicomprensiva, sin admitir que en su seno puedan coexistir una pluralidad de opciones de distinto signo político, ni permitir cauces democráticos libres para que estas opciones se ex- 
presen. No debe llevarnos a engaño la circunstancia de que el nacionalismo permita la celebración de elecciones, obligado por la evolución de la cultura política de nuestro tiempo. Tales elecciones se hallarán siempre viciadas por la acusación nacionalista de que los partidos que no se adhieran al proyecto nacional, son traidores o sucursalistas de visiones políticas no sometidas al canon de la ortodoxia nacionalista.

La teoría de la razón de Estado debe su origen a las tesis políticas renacentistas de Francesco GUICCIARDINI y MAQUIAVELO. Friedrich MEINECKE ha seguido los avatares históricos de la idea de la razón de Estado y de sus proyecciones en la práctica política, que han sido muchas, y que han pretendido sustraer la acción del Estado de las reglas de la moral y del Derecho. Según los presupuestos de esta doctrina, en nombre del interés público se justifica la mentira, la opresión, la violencia y el crimen, porque para el interés del Estado todo está permitido: el fin justifica los medios. La razón de Estado consiente al gobernante suscribir tratados y pactos, bajo reserva mental, a sabiendas de que en función de sus intereses podrá incumplirlos. Esta concepción está presente en la ejecutoria del nacionalismo político, que simplemente se ha limitado a sustituir la idea de Estado por la de Nación, En un intento de legitimar, en nombre del interés nacional, la agresión a otras comunidades políticas o la negación de derechos y libertades de quienes no comulgan con el proyecto nacional.

El nacionalismo suele apelar, como alibí legitimador, a la supuesta validez de su ideología para contribuir a la liberación de naciones o pueblos oprimidos. Tal pretensión me parece infundada, ya que para el logro de esos objetivos legítimos se debe acudir a las normas del Derecho internacional público y, siempre, a la garantía de la universalidad de los derechos humanos. Constituiría un manifiesto oxímoron pretender la libertad de pueblos o naciones a través de una ideología que intrínsecamente niega la libertad.

Respondiendo a tu pregunta, debo precisar, para evitar equívocos, que no todas las actitudes políticas que invocan las nociones de Patria o de Nación, deben ser consideradas nacionalistas. Solo debe adscribirse a esa ideología la apelación a dichos conceptos, realizada desde las premisas políticas, a las que he tenido ocasión de referirme, como caracterizadoras del nacionalismo. En aras de esa exigencia de precisión, conviene mantener la diferencia, acorde con planteamientos actuales de la teoría política y el constitucionalismo, entre el patriotismo nacionalista y el patriotismo constitucional. Este último se caracteriza por la adhesión, la defensa y el compromiso, realizado desde una actitud racional, consciente y libre, con los valores y los derechos fundamentales, cuya propia denominación evoca su cometido fundamentador del Estado de Derecho.

El nacionalismo político aparece, por tanto, como una ideología de zafio cuño tribal y excluyente, que allí donde ha impuesto su sinrazón ha hecho cabalgar a los cuatro jinetes del Apocalipsis: el hambre, la peste, la guerra y la muerte.

El hambre, porque sus promesas de un sueño de bienestar, se traducen en la pesadilla del empobrecimiento. Al nacionalismo político le es implícito un modelo económico autárquico, que es abiertamente incompatible con la interdependencia de procesos económicos que caracterizan a la sociedad global. Además, esta ideología crea un clima totalitario de falta de libertad y de seguridad jurídica, que impide cualquier desarrollo normalizado de la economía. 
El nacionalismo político representa también la peste, en cuanto promueve una enfermedad moral en la sociedad, en la medida en que su cruzada contra los chivos expiatorios promueve en la comunidad el discurso del odio.

«El nacionalismo es la guerra» según la certera expresión de François Mitterrand. El nacionalismo político por su carácter tribal, engendra posturas supremacistas y, en definitiva, racistas, que generan siempre un factor de violencia en el plano interno y en el internacional. Esta ideología ha sido, en gran parte, responsable de las grandes tragedias contemporáneas: las guerras mundiales, la guerra de los Balcanes, con sus inconcebibles episodios de limpieza étnica, los diferentes conflictos tribales africanos y asiáticos motivados por el odio étnico...

El nacionalismo político representa la abolición, que es tanto como decir la muerte, de valores que son básicos para la calidad de vida cívica de una sociedad bien ordenada. Esta ideología proyecta sobre el imaginario colectivo determinados tópicos, como los referentes al vínculo de pertenencia, la apelación a hechos diferenciales para justificar la desigualdad de derechos, el derecho a decidir, que respetará, si y solo si, la decisión se adecua a su conveniencia. Por eso, el nacionalismo subordina la lealtad política y el respeto a la ley a los pactos y acuerdos a lo que considera como supremo interés de la Nación. A través de esas falacias se anulan valores que son básicos para el correcto funcionamiento de una sociedad libre y democrática: la solidaridad, la tolerancia, la concordia y el pleno disfrute de los derechos en condiciones de igualdad.

Tengo para mí que llegará un tiempo, espero que no muy lejano, en el que, el desarrollo de la cultura política y de la consciencia cívica, reputen al nacionalista como un enemigo del género humano, cuya conducta se considere tan vergonzosa e inaceptable como la del antropófago, el esclavista o el maltratador de género.

M. A.: Cuando afirmas que el nacionalista es un «enemigo del género bumano», ¿estás teniendo en cuenta de alguna manera al Derecho natural? Y dado que quienes apelan de manera explícita al Derecho natural en nuestros días suele ser gente vinculada o perteneciente a la Iglesia católica, ¿qué juicio te merece el apoyo que de manera, al parecer, muy mayoritaria presta al nacionalismo catalán la Iglesia de Cataluña?

A.-E. P. L.: Estimo que, en efecto, existe una abierta enemistad entre lo que representa el nacionalismo y los valores humanistas, que puede tener una lectura en clave de Derecho natural.

La tradición iusnaturalista de inspiración humanista, racionalista, universalista y cosmopolita, en la que el neoiusnaturalismo que defiendo halla su entronque, ha hecho del cultivo de la razón y de la libertad el rasgo distintivo de su ideario. La apelación a esos valores de racionalidad y libertad representan la más radical oposición a los disvalores de la irracionalidad y el totalitarismo, que son constitutivos de la ideología nacionalista.

Tienes razón en cuanto afirmas sobre la apelación al Derecho natural por parte de personas pertenecientes o vinculadas a la Iglesia católica en nuestro tiempo. Conviene advertir, sin embargo, que esas apelaciones no tienen un significado unívoco. Es muy diferente la concepción del Derecho natural que se expresa en los Discursos y en los Radiomensajes de Pío XII, que la explícita fundamentación iusnaturalista que dimana de la Pacem in Terris de Juan XXIII, por poner un ejemplo. Tampoco resulta 
infrecuente hallar citas del iusnaturalismo tomista en los principales representantes de la teología de la liberación y remisiones a esa misma doctrina en los sectores católicos más involucionistas. En cualquier caso, estimo que el iusnaturalismo católico no puede avenirse con el nacionalismo político, por fidelidad al intelectualismo o racionalismo de Tomás DE AQUINO y por la propia vocación ecuménica de la Iglesia.

En esa tendencia básica se pueden producir excepciones y la actitud mayoritaria de la Iglesia católica catalana, tal como indicas, podría ser una de ellas. El fenómeno tal vez pudiera encontrar explicación en la reminiscencia de determinadas circunstancias históricas. No se debe olvidar la adhesión mayoritaria del clero vasco y catalán al carlismo durante el siglo XIX, ideología que refutaba la sociedad fundada en la racionalidad, la libertad y la laicidad, en nombre de los sentimientos tradicionales y del antiliberalismo.

No conozco que se hayan producido invocaciones al Derecho natural por parte de clérigos catalanes separatistas. A través de los medios de comunicación, se han difundido algunas referencias de representantes de la Iglesia catalana al derecho de los pueblos y de las naciones a la defensa de su identidad. Tales afirmaciones me parece que responden a un planteamiento confuso e inepto. Confunde dos conceptos diferentes: el nacionalismo político y el nacionalismo cultural. Este último, defiende la peculiaridad de las tradiciones culturales, integradas por la lengua, el patrimonio histórico-artístico, el folklore..., propios de las distintas comunidades o grupos sociales. A diferencia del nacionalismo político, el nacionalismo cultural parte de premisas pluralistas, sustenta el multiculturalismo y defiende la igualdad de trato, negando la discriminación y el supremacismo de cualquier comunidad cultural. El derecho a la identidad cultural está plenamente garantizado en nuestro texto constitucional y en el vigente Estatuto de Autonomía de Cataluña. Por ello, quizá conviene recordar aquí la enseñanza del Menón platónico, de que nadie puede pedir lo que ya tiene, precisamente, porque ya lo tiene. Por eso, esas apelaciones al derecho a la identidad involucran, de forma deliberadamente confusa y confundidora, dos reivindicaciones distintas: el derecho a la identidad cultural, exigencia que carece de sentido, porque ese derecho ya se halla plenamente reconocido, con un pretendido derecho a la sedición, que contraviene abiertamente el orden jurídico del Estado de Derecho.

Se me podrá objetar que mi visión de la ideología nacionalista es apocalíptica y que mi descalificación de esa tendencia política paga tributo al exceso. Empero, confío en que quien reflexione con ánimo sereno y ecuánime sobre la responsabilidad que ha tenido el nacionalismo en algunos de los episodios políticos más dramáticos y lamentables de la era contemporánea se muestre proclive a comprender y, en el mejor de los casos, a compartir algunas de las inquietudes que aquí he expuesto.

M. A.: Te preguntaré ahora algo sobre el futuro. Me gustaría que nos dijeras cómo ves el futuro (más o menos inmediato) de la filosofía del Derecho en España y fuera de España. ¿Está «bien orientada» la disciplina, o sea, el trabajo que llevan a cabo quienes pertenecen a la comunidad iusfilosófica, o te parece que babría que introducir algún cambio por lo que se refiere a los principales temas de estudio abordados, a la metodología empleada o a la propia organización de la comunidad?

A.-E. P. L.: Veo el futuro inmediato de la Filosofía del Derecho con sentimientos contrapuestos de inquietud y de optimismo. De inquietud, porque estimo que la 
orientación fundamental de los estudios jurídicos que dimana del Plan Bolonia tiende a potenciar el estudio de las distintas ramas del Derecho positivo en detrimento de las materias fundamentadoras o de las denominadas Ciencias jurídicas básicas. En la mayoría de los Estados de la UE, la filosofía jurídica se estudia en algunos cursos especializados de Master o en el Doctorado. Solo en determinados planes de estudio se incluyen como materias obligatorias del Grado, una Teoría del Derecho o una Metodología jurídica, que tienen un carácter propedéutico para el estudio de las disciplinas jurídico-positivas. En los países anglosajones, la estrecha vinculación de la Filosofía del Derecho con la Filosofía Moral y Política ha potenciado programas de investigación interdisciplinarios. Pero esto ha implicado, en muchas ocasiones, la ubicación de esas enseñanzas en las Facultades de Filosofía, de Humanidades o de Ciencias Sociales o Políticas y su consiguiente desaparición de los centros universitarios jurídicos. En estos se ha tendido a su sustitución por materias de estricta significación jurídica, como la Teoría del Derecho, la Jurisprudence, el Derecho Comparado o la Sociología del Derecho.

En España la situación de las disciplinas iusfilosóficas en las Facultades de Derecho, tras la reforma de Bolonia, ha respondido, en ocasiones, más que a razones científicas a las relaciones de nuestros docentes con los poderes académicos. En el mejor de los casos, se ha conseguido mantener como materias obligatorias la Teoría del Derecho y la Filosofía del Derecho, si bien con una significativa reducción de créditos; han dejado de ser asignaturas de ciclo anual, pasando a ser cuatrimestrales. Así ha ocurrido, por ejemplo, en mi Universidad de Sevilla, donde se ha querido compensar esa disminución de créditos con la atribución a nuestro Departamento de dos materias cuatrimestrales optativas: la Teoría de la Justicia y la Metodología del Derecho, así como con la presencia de nuestras disciplinas en los planes de estudio de los dobles grados, de los cursos de master y del doctorado.

El principal defecto de los nuevos planes estimo que reside en que fuerzan a compendiar los programas previstos para cursos de nueve meses lectivos, en un cuatrimestre, lo que obliga a eliminar algunas materias que son importantes, o a ofrecer de todas una visión tan esquemática que puede redundar en la propia calidad de la enseñanza.

Un aspecto positivo del Plan Bolonia era su exigencia de una evaluación continuada del aprendizaje del alumno y pretendía potenciar su presencia, así como su participación activa en el desarrollo de las actividades académicas. Estos buenos propósitos requerían, para su éxito, estructurar la enseñanza en grupos reducidos de alumnos. Como no se ha producido la necesaria contratación de profesorado, acorde con las exigencias de ese nuevo modelo de enseñanza, las expectativas cifradas en esa innovación se han visto, en gran medida, frustradas.

Esos motivos de preocupación podrían suscitar meditaciones melancólicas sobre el porvenir de nuestra disciplina, pero se ven, por fortuna, contrapuntados por un principio de esperanza. En mi distrito universitario, se ha producido una circunstancia que invita al optimismo. Se trata de un proyecto, en avanzada tramitación, de instaurar un doble grado de Derecho y Filosofía, atendiendo a la demanda del alumnado y a la experiencia de un significativo número de estudiantes que, en los últimos años, han cursado ambas titulaciones de forma simultánea o sucesiva. De ello se desprenden dos consecuencias de signo muy positivo: que el interés por las materias iusfilosóficas 
sigue vivo y que, en esa nueva titulación, cabe conjeturar que la presencia de nuestra disciplina será relevante.

Me preguntas lo que opino sobe si está bien orientado el trabajo de quienes pertenecen a la comunidad iusfilosófica. Tu pregunta pienso que evoca la imagen de una comunidad de estudiosos, que coinciden en la forma de entender y desarrollar el quehacer iusfilosófico. Creo que la realidad no responde a esa suposición. Por referirme solo al caso de España, recordarás que, hace algunos años, Elías DíAZ y Luis GARCÍA-SAN MigUEL, elaboraron unas tipologías, en serio y en broma, sobre las distintas orientaciones teórico-ideológicas de los y las componentes del profesorado de nuestra disciplina. Por tanto, pienso que no puede hablarse de unas formas unívocas de hacer Filosofía del Derecho por parte de quienes integramos la comunidad de sus docentes.

En lo que respecta a la orientación de los estudios de nuestra materia, aquellos que estimo de mayor interés son, básicamente, los que han sido objeto de mis trabajos, a los que he tenido ocasión de aludir en esta entrevista. Ello no significa que lo que ha suscitado mi interés deba ser considerado como lo más importante por los miembros de nuestra comunidad. Importa reconocer, en este ámbito, la máxima libertad científica de todo filósofo del Derecho para elegir sus objetos de investigación. A esa libertad científica le corresponde la consiguiente responsabilidad teórica del investigador, quien deberá justificar el interés de los temas abordados en sus estudios. En lo que hace referencia a los métodos de estudio de la temática de nuestra disciplina, me parece que, para las investigaciones y exposiciones de carácter sistemático, sigue siendo una aportación valiosa la metodología analítico-lingüística. El análisis del lenguaje ha cifrado como una de sus principales metas en el ámbito jurídico el dotar a la ciencia y a la Filosofía del Derecho de un lenguaje riguroso. Para ello, se ha dirigido a esclarecer el significado de los términos fundamentales que aparecen en el discurso jurídico. Su principal preocupación metódica ha sido la de purificar los dominios del Derecho de conceptos inútiles o equívocos desde el punto de vista teórico o de nociones destinadas a enmascarar la realidad desde el plano ideológico. En la actualidad, han contribuido, de manera notable, al desarrollo metodológico de nuestra disciplina las nuevas teorías de la argumentación jurídica. A mi entender ambos métodos son complementarios y debieran utilizarse conjuntamente. El método analítico tiende a garantizar el rigor, claridad y precisión del lenguaje del Derecho, mientras que el argumentativo se hace cargo de los fines prácticos que suelen caracterizar a los razonamientos jurídicos. También mantienen plena utilidad las proyecciones de métodos sociológicos al planteamiento y la elaboración de diferentes estudios relacionados con el objeto de nuestra materia. No sería lícito omitir la referencia al impacto tecnológico (NT y TIC) y científico (neurociencia), en la renovación de diferentes aspectos metódicos de la Filosofía del Derecho del tiempo presente.

Los estudios históricos cuentan en la filosofía del Derecho con orientaciones historiográficas muy elaboradas y que, en mi opinión, mantienen intacto su interés para un conocimiento cabal de la temática iusfilosófica. En esta esfera, me parecen especialmente interesantes los estudios que se dirigen a analizar las transformaciones que han tenido lugar en el tejido institucional, en los conceptos y en las categorías del Derecho, desde la etapa de las codificaciones al mundo global que habitamos en el marco de las sociedades digitales. 
La organización académica de nuestros estudios se lleva a cabo a través de los departamentos. Estos centros de investigación y docencia tienen como principal función fomentar el trabajo intelectual en equipo, con el consiguiente intercambio de ideas y experiencias en el quehacer universitario. Cuando se logra este objetivo, se forman grupos de investigación que permiten profundizar en determinados temas iusfilosóficos, así como ampliar sus perspectivas de enfoque. El principal riesgo de este sistema organizativo reside en la tendencia a que el departamento se convierta en un compartimento estanco, cerrado y con escaso contacto con otros centros o unidades de investigación y docencia. Para evitarlo, conviene que los departamentos de Filosofía del Derecho, o aquellos en los que nuestra disciplina esté integrada con otras áreas, se hallen siempre abiertos a fórmulas de colaboración científica con otros departamentos o centros, de carácter jurídico filosófico o especializados en las distintas ciencias sociales, españoles o extranjeros. En este aspecto, recuerdo como una experiencia muy provechosa, el Programa de Doctorado interuniversitario de Filosofía del Derecho, realizado hace algunos años y cuyas sesiones tuvieron lugar en las Universidades de Alicante, Autónoma de Madrid, Pompeu Fabra de Barcelona, Sevilla y Valencia, que, lamentablemente, no tuvo continuidad.

M. A.: Y, finalmente: ¿Qué consejo le darías a un joven egresado que quisiera empezar ahora a trabajar en el campo de la filosofía del Derecho?

A.-E. P. L.: El consejo que daría (que he dado, cuando he tenido oportunidad de hacerlo) a quien siente la vocación por el estudio de la Filosofía del Derecho se desglosa en un triple estímulo:

En primer término, le aconsejaría que antes de decidirse por un argumento concreto de tesis doctoral o de un programa de investigación, procure tener una visión general de los principales nudos temáticos y problemáticos que informan nuestra disciplina. Es cierto que el saber iusfilosófico es tan amplio, que casi puede considerarse inabarcable. Pero esa circunstancia no exime a quien lo cultiva o pretende cultivarlo, de poseer una visión de conjunto de sus cuestiones fundamentales: sistemáticas e históricas. Tenía tanta razón que hasta le sobraba, ORTEGA, cuando descalificó como «bárbaro especialista» a quien sabe mucho de muy poco. Esa actitud intelectual me parece del todo incompatible con una auténtica vocación iusfilosófica, que reclama cimentarse sobre un amplio horizonte cultural. Partir de esa perspectiva general es lo que permite luego profundizar en aquellos aspectos que el investigador estime que motivan, en mayor grado, su interés. De este modo, se podrán abordar esos temas con mayor provecho teórico, evitando así la frustración que produce, en muchos doctorandos e investigadores, haberse precipitado en la elección de un tema, que luego se comprueba que ha sido estudiado hasta su agotamiento, o recorrer itinerarios teóricos que no conducen a ninguna parte.

En segundo término, le aconsejaría atender a las pautas metodológicas actuales de la investigación de nuestro saber, que postulan una actitud interdisciplinaria. Nunca como hoy se había adquirido la clara consciencia de que nuestra disciplina debe hallarse abierta a una pluralidad de estímulos: filosóficos, sociológicos, tecnológicos..., que contribuyen a situar la investigación de la Filosofía del Derecho a la altura de los apremios de nuestro tiempo. Esa apertura interdisciplinar evita que las investigaciones de nuestra área incurran en un «aislacionismo» o en el divorcio con el desarrollo 
epistemológico de disciplinas que influyen directamente en el significado actual de conceptos y categorías iusfilosóficas.

Terminaría mis recomendaciones instando al iusfilósofo en ciernes a asumir una actitud de autoconvencimiento, algo totalmente distinto de la autocomplacencia, sobre el carácter indispensable de nuestra disciplina para la formación de los juristas. Nada me parece más arbitrario y falaz que el insufrible tópico de quienes consideran a nuestro saber como adjetivo o puramente ornamental en los planes de estudio de las Facultades de Derecho (se suele recurrir a la torpe metáfora de la guinda que corona el pastel). En una Facultad de Derecho, tan importante como el estudio de las distintas materias que se ocupan de la legalidad, lo es el de los criterios de legitimidad, que explicitan el deber ser del Derecho y proponen argumentos para la crítica de la legalidad injusta. Si las Facultades de Derecho desean contribuir a formar juristas y no quedar degradadas a establecimientos dedicados a la producción y reproducción de leguleyos, rábulas o picapleitos, resulta imprescindible la docencia en ellas de disciplinas que propicien la formación cultural y la capacidad crítica del alumnado. A principios del siglo XIX, José M. a ÁlvareZ en sus Instituciones del Derecho Real de España, indicó que una enseñanza del Derecho que no propiciara en los alumnos la inquietud por la justicia, sería responsable de engendrar «buitres togados». Incumbe, en definitiva, a la Filosofía jurídica evitar que los egresados de las Facultades de Derecho puedan convertirse en cómplices de esa lacra que amenaza a las sociedades democráticas, consistente en las distintas formas de corrupción, en especial, de la corrupción política y no quedar tampoco inermes ante los supuestos de abuso del poder. Se trata de hacer definitivamente irrepetible la denuncia, formulada por Alexis DE TOCQUEVILLE, de que en toda situación despótica se advierte la presencia junto al tirano de algunos juristas dedicados a dar una apariencia de racionalidad a lo que son meros designios arbitrarios del poder. 